\title{
IN-BETWEEN POTENTIALS
}

\section{Constructing Playgrounds out of Urbanity's Leftovers}

by

Katherine Pyle

A thesis submitted to the Faculty of Graduate and Postdoctoral Affairs

in partial fulfillment of the requirements for the degree of

Master of Architecture

Carleton University

Ottawa, Ontario

(C) 2011

Katherine Pyle 


$\begin{array}{ll}\begin{array}{l}\text { Library and Archives } \\ \text { Canada }\end{array} & \begin{array}{l}\text { Bibliothèque et } \\ \text { Archives Canada }\end{array} \\ \begin{array}{l}\text { Published Heritage } \\ \text { Branch }\end{array} & \begin{array}{l}\text { Direction du } \\ \text { Patrimoine de l'édition }\end{array} \\ \begin{array}{l}\text { 395 Wellington Street } \\ \text { Ottawa ON K1A ON4 } \\ \text { Canada }\end{array} & \begin{array}{l}\text { 395, rue Wellington } \\ \text { Ottawa ON K1A ON4 } \\ \text { Canada }\end{array}\end{array}$

Your file Votre référence

ISBN: 978-0-494-83186-1

Our file Notre référence

ISBN: $978-0-494-83186-1$

\section{NOTICE:}

The author has granted a nonexclusive license allowing Library and Archives Canada to reproduce, publish, archive, preserve, conserve, communicate to the public by telecommunication or on the Internet, loan, distribute and sell theses worldwide, for commercial or noncommercial purposes, in microform, paper, electronic and/or any other formats.

The author retains copyright ownership and moral rights in this thesis. Neither the thesis nor substantial extracts from it may be printed or otherwise reproduced without the author's permission.
AVIS:

L'auteur a accordé une licence non exclusive permettant à la Bibliothèque et Archives Canada de reproduire, publier, archiver, sauvegarder, conserver, transmettre au public par télécommunication ou par l'Internet, prêter, distribuer et vendre des thèses partout dans le monde, à des fins commerciales ou autres, sur support microforme, papier, électronique et/ou autres formats.

L'auteur conserve la propriété du droit d'auteur et des droits moraux qui protège cette thèse. Ni la thèse ni des extraits substantiels de celle-ci ne doivent être imprimés ou autrement reproduits sans son autorisation.
In compliance with the Canadian Privacy Act some supporting forms may have been removed from this thesis.

While these forms may be included in the document page count, their removal does not represent any loss of content from the thesis.
Conformément à la loi canadienne sur la protection de la vie privée, quelques formulaires secondaires ont été enlevés de cette thèse.

Bien que ces formulaires aient inclus dans la pagination, il n'y aura aucun contenu manquant.

\section{Canadä}




\section{Please note:}

The information from the original title page for this thesis has been transferred to the Carleton University standard title page template for theses. The student's original title page is still included. 
IN-BETWEEN POTENTIALS

Constructing Playgrounds out of Urbanity's Leftovers

By Katherine Pyle, B.A.S.

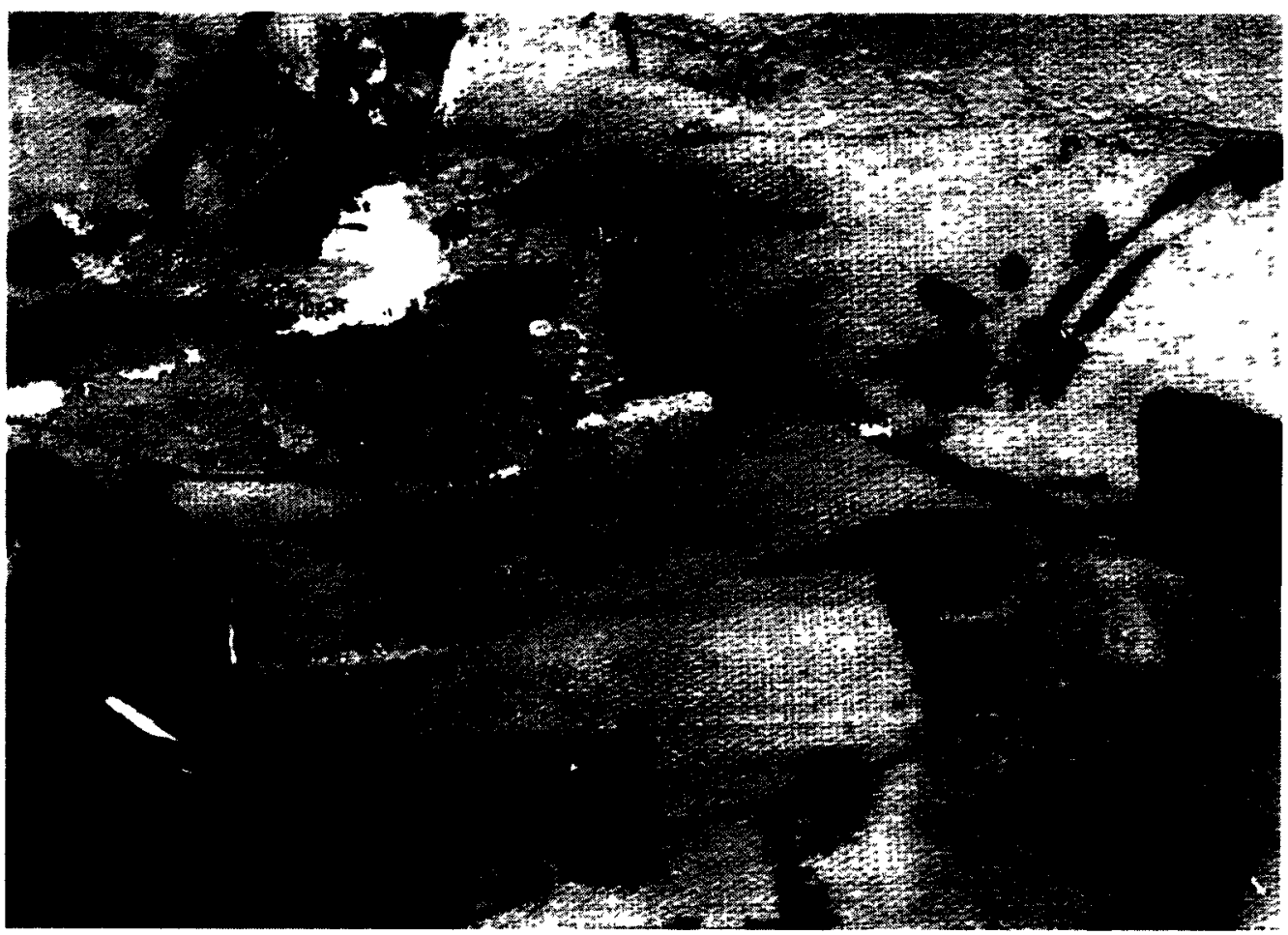

A thesis submitted to the Faculty of Graduate Studies and Research

in partial fulfillment of the requirements for the degree of Master Of Architecture (M.ARCH. Professional)

Azrieli School of Architecture and Urbanism, Carleton University, Ottawa, Canada

2011 @ Katherine Pyle 
Leftover spaces are pockets of undefined space unavoidably created in the wake of urban planning. They are seen as waste because they are not considered to be profitable; however, as an exploratory space they possess the inherent potential to host an infinite number of uses at any moment. Regardless of this true value, rather than embracing and adding to this indeterminate quality, these leftovers are often 'solved' with the very processes that created them. This inevitably creates more leftovers and perpetuates the cycle. Instead of resolving the leftover urban spaces through the closed-process of planning, this thesis explores the possibility employing the phenomenon of play to break this cycle and allow a useless leftover space in the urban fabric to reveal its embedded diverse strengths.

The phenomenon of play in this thesis refers to the act of a child using imagination and creativity to transform his surroundings and manipulate rules to satisfy his purpose. Rules, an essential component to the nature of play, allow play to exist and progress. They are the tools which both define the framework of and give infinite variation to play. The players' initial acceptance and subsequent manipulations of the rules throughout the play process stimulate their imaginations and separate play, and its world, from the ordinary.

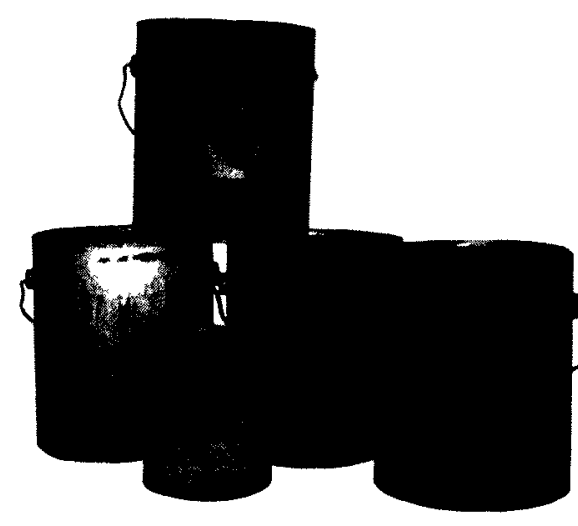

For architecture to break the leftover cycle, it must observe an alternative way of creating rules for architectural design. Similar to the way children animate their play via the creation and manipulation of the rules, architecture should be born from the intrinsic needs of the site, users and tectonic construction. Under this theoretical premise, the architecture proposed by this thesis is the natural outcome of a set of physical rules observed for a space that embodies the same qualities found in the rules children create for play. The architectural rules promote the potentials inherent to leftover spaces by encouraging a user to engage the space and use his imagination to alter it to fulfill his needs. This renders the space truly indeterminate and transforms it into an urban playground. 


\section{FOR MY FAMILY I}

To Barbara and Dennis for your unwavering support my whole life and for every opportunity you have made sacrifices to give me.

To Beth and Thomas for your generosity and for the positive influence you've had on me; I can't sneak anything past either of you, you're both so stealthy.

To my Friends, both in the program and outside of it, for your steadfast belief in me and for ensuring that my days are never short on laughter. 


\section{ACKNOWLEDGEMENTS ।}

I would like to thank my advisor Qi Zhu for her guidance, insight and, most of all, passion. Without her dedication, this thesis would not be what it is.

Thank you for encouraging my potential and playing along. 
ABSTRACT

ACKNOWLDEGEMENTS

INTRODUCTION

FUGITIVE ARCHITECTURE I LEFTOVER SPACES.

PARADOXICAL SPACES I CHARACTERISTICS OF LEFTOVERS

CYCLIC ATTITUDES I THE ACT OF TRANSGRESSION

THE PERFORMANCE OF AN ACT APART I CHILD'S PLAY.

THE RULES OF PLAY | PLAYGROUNDS

DETERMINING THE INDETERMINATE I LEFTOVERS AS PLAYGROUNDS.

JOINING THE GAME I INSIPIRING PLAY

THE UNDERPASS AS A LEFTOVER I THE PROJECT SITE.

AN URBAN JOINT I PRE-EXISITING CONDITIONS

IN-BETWEEN POTENTIALS I THE PROJECT PROPOSAL.

THE PLAYERS | THE PLAYGROUND | THE PLAY

CONLUSION I BEGINNING PLAY.

GLOSSARY I SITE JOURNALS I LEFTOVER MAPPING I SURVEYS 
Figure 1.0

A Picture is Worth a Thousand Words.

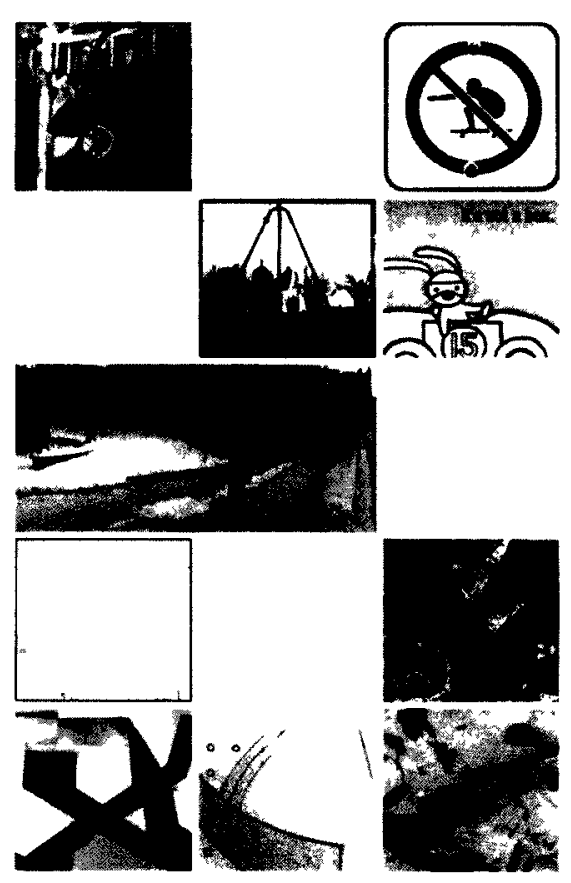

The motive of this thesis is to draw attention to the potential leftover spaces possess and demonstrate how architecture can embrace this potential to encourage human interaction, expression and participation. A leftover space inherently possesses indeterminacy, a quality generating the ability to provide every person with a space uniquely their own. The lack of definition surrounding these spaces allows any person to enter it and determine its function for the duration of their stay. By observing the activities that repeatedly manifest themselves there, often because no other space exists for them, architecture can be used to compliment these spaces and promote their use.

Currently, the negative attitudes directed towards leftover spaces are reflected in their physical condition. Their derelict circumstance which arises from their neglected state causes certain actions to be taken against them. Among those actions are the erection of fences, implementation of surveillance and assignment of a determinate program to inhabit the space and dictate its use. These attitudes create crippled leftovers, preventing the spaces from realizing their full indeterminate potential. This is the kind of space that is the site chosen for this thesis. The Underpass at Rideau St. and Colonel By Dr is a residual of the road system implemented after the closing of the Train Station in 1966. Located on the defining corner of the downtown Rideau district, this space has the potential to be more than a mere pedestrian link. To successfully implement architecture into this or any leftover space, there must first be a firm understanding of their fundamental qualities. A comprehensive investigation uncovering their traits: their formation, location, use and connection, to each other, their users and surrounding urban fabric, reveals their character and value to which architecture must respond. Careful site observations of the Underpass reveal a series of activities, in addition to the walkway, that are intrinsic to the site such as busking, street dwelling, skateboarding, performing and vending. The architecture proposed by this thesis is designed to respond to the inner needs of the space, and its users, and promote the embedded indeterminate potential it possesses. Development of an architecture capable of this flexibility relies on new strategies of designing architecture. This thesis investigates how the deployment of various play theories can be fused 
into architectural design practices. In summary, play is the process of a person entering a playground, accepting the rules of the game and then creatively operating within them. These rules are absolutely binding, for without them the game would cease to exist. However, they offer an infinite variation within the framework they create and can be manipulated by the players. For example, to play music one first has to accept the rules of scales and notes, however even by doing so, the possibility of what can be written is still endless. ${ }^{1}$

This thesis proposes a set of architectural rules for the site of Ottawa's Underpass. These rules are formulated in reference to its current functions, both formal and informal, how the space connects to its surrounding and what features it has that promotes both existing uses and potential ones. It is these rules that will both entice users to play in the space and encourage them to play with the space; adapting it to the varied needs of each user's play, and creating a truly indetermınate space.

\footnotetext{
${ }^{1}$ Hulzınga, Johan Homo Ludens Boston Beacon Press, 1967 p 132
} 
In an ideal world free of nature's negative attitude, an object would reach zero value and zero expected life span at the same instant and then disappears into dust. But in reality it usually does not do this, it just continues to exist in a timeless and valueless limbo where at some later date (if it has not by that time turned or been made into dust) it has the chance of being discovered.

-Michael Thompson, Rubbish Theory: The Creation and Destruction of Value 


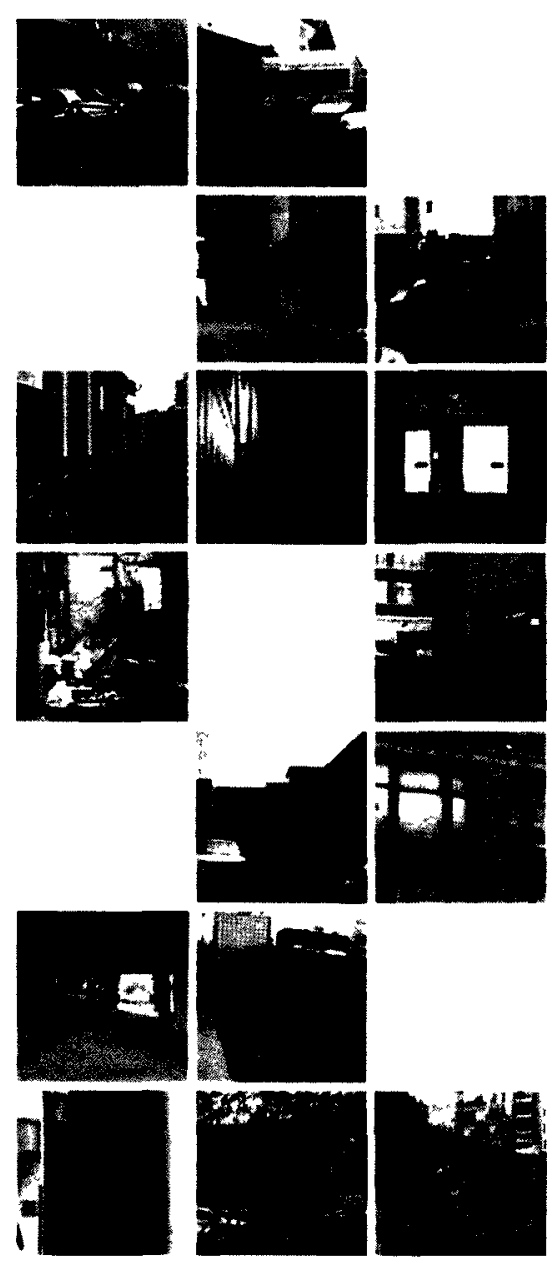

Figure 2.0

Leftover spaces in downtown Ottawa.
Woven into the urban fabric of every city are pockets of unused space; space that was either not accounted for in a design, that was created as the result of an imposed structure on an existing condition, or that was once in use but has since been abandoned. Many architects and planners see these spaces as a waste, and label them as such: wasteland, dead zones, voids, etc. They are viewed as counteracting the image of a clean, wholesome city primarily due to their aesthetics and informal usage. These spaces are often dark, disorderly and dirty. Thus they are looked upon with disapproval and an anxiety that stems from a common belief that dirt offends against order. ${ }^{2}$ Furthermore, these aesthetically displeasing spaces accommodate many activities that are opposed by formal urban society. The activities that materialize in leftover spaces are often the ones that do not have a place of their own in the built environment; they are leftovers themselves, informal, contradictory to the ideals of the structured urban fabric and deemed unworthy of space. In addition to the expendability of these activities, the limited quantity of space in cities constantly increasing their potential monetary value and the undesirable atheistic often displayed by them, cause leftovers located in cities experience a strong push to be repurposed for formal uses.

Though they are not valuable building zones, leftover spaces do have their own programs beyond the obvious determinate functions such as parking, waste disposal (dumpsters), delivery zones, etc. that would otherwise require expensive solutions. These programs are their "informal" functions defined by the users and although they are conventionally seen as unproductive because their profit cannot be quantified financially, the leftover spaces termed as wastelands, dead zones, etc. possess a strong inner

${ }^{2}$ Doron, Gil M. 'The Dead Zone and the Architecture of Transgression.' City. Vol.4 number 2, 2000: 247-263. p.249 
life. In his article Junkspace, Rem Koolhaas refers to this phenomenon when he wrote "Junkspace's entropic plan was quick to consume each of these sites of playful re-construction."3

Here instead of terming the leftovers as junkspace, it is the built environment to which he assigns this title. The leftover spaces are instead 'sites of playful re-construction' - a term closer to the truth for those who actively use them. Gill Doron, a writer who has extensively researched leftover spaces, wrote that while "the term colours these spaces in overly negative hues, they are often considered to be assets." Furthermore, rather than judging these spaces by the order of the built environment, Doron urges people to realize that "the nature that had taken hold of these places and the informal activities that are there are not disordered, but simply an order of a different kind." known to "harbour various spatial, natural, architectural, and social qualities that cannot be found in and are often actively excluded from, other urban spaces, including the formal public space." 6 It is from the indeterminate quality inherent to every leftover space that these traits steam.

\section{PARADOXICAL SPACES I THE GAP CONDITION}

Unlike any other space in the built environment, these undefined gaps have a unique ability to adapt to the needs of each user, providing them with an opportunity that structured society does not. Hilarey Powell, an artist and writer who deals with urban spaces and waste, writes about leftover spaces, in reference to Koolhaas' Junkspace:

\footnotetext{
${ }^{3}$ Powell, Hilary "Recycling Junkspace finding space for 'playtıme' in the city "The Journal of Architecture Volume 10, Aprl 2005 201-221 p 216

${ }^{4}$ Doron, GIll badlands, blank space, border vacuums, brown fields, conceptual Nevada, Dead Zones www field-journal org

Vol 1 (1) ISSN 1755-068 p 12
5 Doron "The Dead Zone and the Architecture of Transgression " p 249

${ }^{6}$ Doron " badlands, blank space, border vacuums, brown fields, conceptual Nevada, Dead Zones ." p 15
} 


\begin{abstract}
"such sites and spaces are not waste. They can be described as Junkspace, but rather than being associated with the throwaway consumer culture of junk mail/food/architecture as espoused by Koothaas, 'junk' here returns to its roots as differentiated from rubbish or waste due to its potential for re-use. It is a junk space of potential, awaiting re-entry to a system of value (economic, social, political ...) and could be seen as the antithesis of Junkspace."
\end{abstract}

Powell suggests that the potential for adaptive re-use that rests within a leftover space, here termed indeterminacy, implies a separation from the formal built environment. It is these spaces that provide a flexible haven that support all ways of life - fostering creativity and contemplation. Thus indeterminate leftovers act as 'others' to the structured, determinate city. ${ }^{8}$

The other condition experienced by leftovers is accentuated by their physical existence as a gap in the urban fabric. An existence in the 'gaps' of a city provides a visual confirmation that these spaces are, in fact, separate from it. In addition to this, the neglect they experience from avoidance or ignorance based on their 'disorderly' conduct further encourages this perceived spilt. The result of this perception is the impression that these spaces are not bound by the rules of society. They are physical fissures in a city and are therefore gaps in its jurisdiction as well. Therefore each user of a leftover is provided the opportunity to formulate their own rules for the space upon entering it. Furthermore, the implicit freedom they convey converts these spaces into places that provide space for critical reflection on the accepted standards of society. ${ }^{9}$ After the fall of the wall, Berlin experienced this phenomenon when changes in the political system created large pockets of leftover space. Without a sense of clear ownership, the spaces played host to squatters who then began adapting them to fulfill the needs that the built environment did

\footnotetext{
${ }^{7}$ Powell "Recycling Junkspace: finding space for 'playtime' in the city." p.216

${ }^{8}$ Doron ". badlands, blank space, border vacuums, brown fields, conceptual Nevada, Dead Zones " p 17

9
9
} 


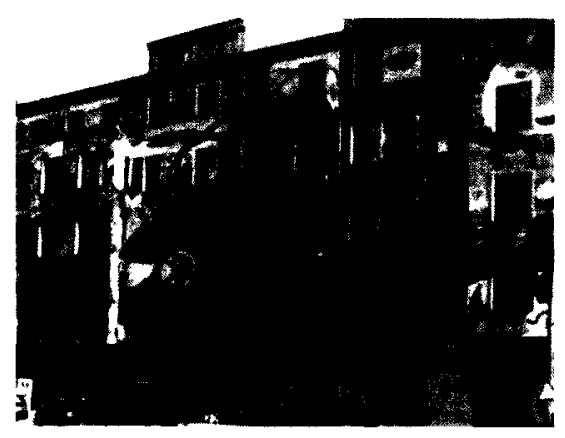

Figure 2.1

Squatter Residence Freidrichshain, Berlin.

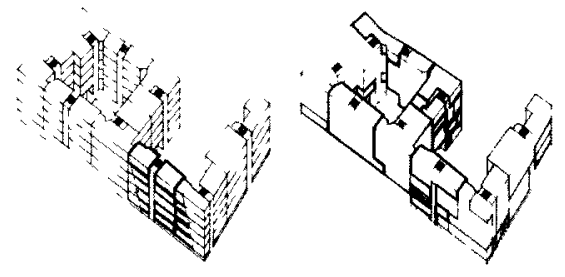

Figure 2.2

Comparison of the spatial arrangement in Brunnen Str 687 and the conventional occupancy arrangement of a courtyard building. Areas are colour coded to match the case study's plans. not. ${ }^{10}$ Through these spaces the squatters were able to succeed in fulfilling their desires while at the same time calling into question the socially accepted standard of what a space should provide, etc.

Leftover spaces have this unique ability to address urban issues because each created space is a direct result of the actions of an evolving society. Each unique site inherently speaks to the specific culture that created them, allowing one to "experience the City through what has been cast off." ${ }^{11}$ The creation of these spaces therefore creates a paradoxical condition between them and their host cities. Each space holds the essence of the culture that created them while at the same time providing users with the best opportunity to "question the accepted norms, by highlighting flaws and generating new practices, new ecological habitats, new sub-cultures and new economies." ${ }^{12}$

In addition to this quality, their 'gap' existence creates a similar paradoxical condition with respect to time. When a space either experiences abandonment or was never assigned an original function and it loses all connection to the past and exists in a suspended reality until that unknown moment in the future when it becomes defined. Until that moment however, time has no authority over it. It exists within a gap outside of the past/present/future linear time line that otherwise is perceived as being continuous; it is suspended in the present. In his book The Aesthetics of Disappearance, Paul Virilio speaks to a similar occurrence that takes place during the process of perceiving reality which he termed picnolepsy. Picnolepsy is where "perception is made of breaks, absences, dislocations as well as by the capacity to produce patchworks of various contingent worlds." ${ }^{13}$ According to him, humans stitch together their fragmented pieces of experience to create what is believed to be a continuous vector of reality, however gaps do exist and

\footnotetext{
${ }^{10}$ Sheridan, Dougal. "The Space of Subculture in the City: Getting Specific about Berlin's Indeterminate Territories" Field. Vol.1 (1). ISSN: 1755-066. Sept. 2007

${ }^{11}$ Powell. "Recycling Junkspace: finding space for 'playtime' in the city." p.202

${ }^{12}$ Williams, Emma. "Spaces of Indeterminacy." The Theory Forum: Architecture and Indeterminacy. Nov. 2007. Accessed: Feb.

2010. URL: http://www. shef.ac.uk/architecture/main/gallery/gal/diploma/theoryforum07/essays/emma williams.pdf

${ }^{3}$ Virilio, Paul. The Aesthetics of Disappearance. Los Angeles: Semiotext(e), 2009. p.11
} 
these breaks in the time line alter everyone's reality. He continues by saying that "it is the 'in-between state' that make the impossible, supernatural and marvelous visible." ${ }^{14}$

Likewise the gap in time experienced by leftover spaces is where the freedom to adapt comes from. Unlike any other space, the leftover finds itself free of the one rule binding everything. Its reality is altered to whatever function currently inhabits them, regardless of time. When a function leaves, the space lies in wait of the next. Thus it is an existence in this temporal gap while at the same time being a physical gap in the city that gives leftover spaces their indeterminate quality. The gap condition affords these spaces the freedom they need to be adaptable to the needs of future visitors.

\section{CHARACTERISTICS OF LEFTOVERS I SYMPTOMS OF INDETERMINACY.}

The gap condition also implies that each space is unique because the activities it responds to are site specific and are always changing. Each space is thus an other specifically to the city which created it and no two leftover spaces are identical. Therefore, an entirely inclusive definition of a leftover space cannot be made. Instead commonalities can be found between them to provide a general overview. Typically, leftover spaces posses the following traits:

These spaces exist in either of the following conditions:

- As a residual space that was created by urban planning, though not intentionally as a part of the design. Such spaces include alleys, bridge underpasses, etc.

- As a site of abandonment; either a lot or building, that is left without a current formal usage.

The aesthetic features can vary, but often include being dark, dirty, and disorderly.

\footnotetext{
${ }^{14}$ Virilio. The Aesthetics of Disappearance. p.11
} 
- Without an identity these spaces foster potential, fantasy and expectations within them. They trigger and embody limitless choice and desire.

They are assumed to be unproductive spaces, but can still be productive in a way that cannot be quantified financially.

- $\quad$ These spaces are frequently used for informal or marginal activities of a temporal nature, that add character to the site but do not define it; they are continuously changing.

- $\quad$ They live in a temporal break, a hiatus, and exist in the continuous present.

- These spaces act as others to the city.

- These spaces are 'constitutive outsides' in both their relationship to the city and in the relationships between inhabitants.

- These are paradoxical spaces.

\section{CYCLIC ATTITUDES I THE DESIRE TO ERASE}

Despite the many positive characteristics, it is the appearance of such sites that is used as the main criterion to judge them. ${ }^{15}$ Their true value as an exploratory space is ignored, ${ }^{16}$ and leftover spaces are consumed by the formal built environment. However, their conversion into a determinate space that is recognized as being appropriate for only one function has the opposite effect of what is intended. This process, as Doron points out, cannot

"delete the systems that produced these 'voids' and waste [because] these strategies and their methods are part of the same economic, social, political and planning systems that created these places from the beginning. Replanning, redeveloping, revitalizing and Renaissanciation will simply erase the evidence of the crime. Furthermore, it will

\footnotetext{
${ }^{15}$ Doron " .badlands, blank space, border vacuums, brown fields, conceptual Nevada, Dead Zones..." p.14

${ }^{16}$ Doron " .badlands, blank space, border vacuums, brown fields, conceptual Nevada, Dead Zones. ." p.16
} 


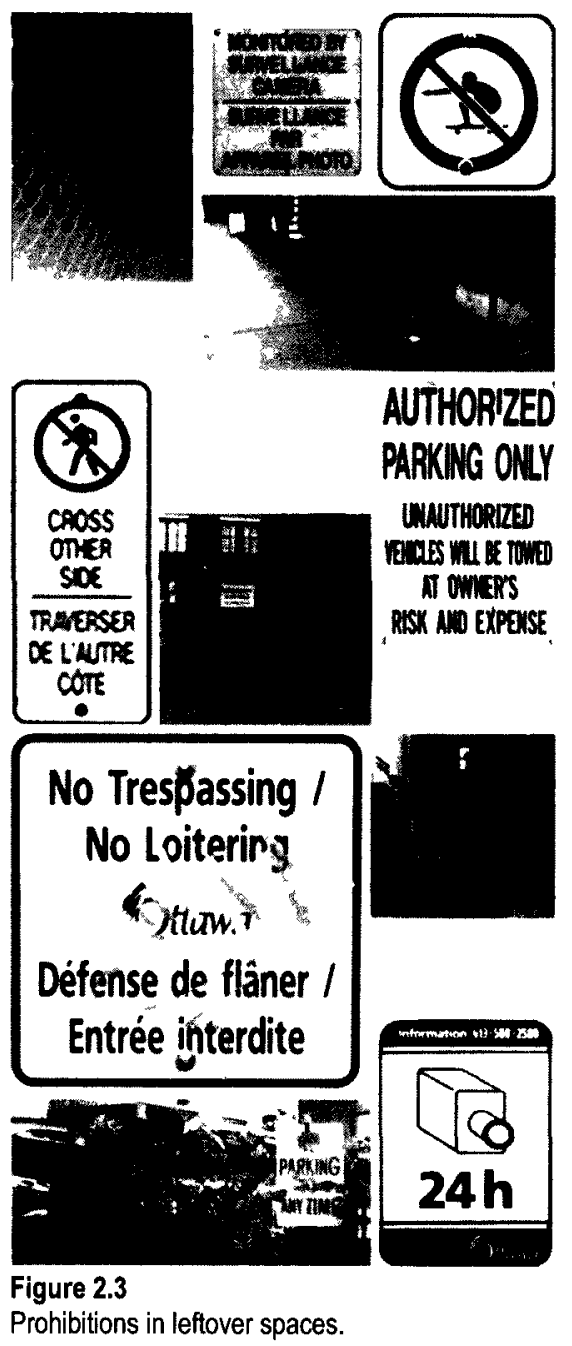

exterminate the victims who found refuge in the waste that these systems, for their own sake, deliberately produced." 17

Instead of re-purposing the space to create a more complete urban fabric, the site is fragmented into more leftovers which invoke feelings of under-use and wasted potential rather than a want to engage. Furthermore, the other activities that need the space and naturally want to take place there are evicted, resulting in the creation of architecturally designed voids, where the citizens who did not previously use the space continue to avoid it and those who did cannot

Why then do architects and planners insist on trying to fix these spaces, and with the processes that caused them in the first place? The abandoned structure is torn down to be replaced by a "useful" building that, when its determinacy leaves it, will experience the same process of abandonment. Similarily, the urban gaps are filled with programs that inadequately consume them, leaving smaller yet similar fissures. Doron writes that leftover spaces invoke anxiety in architects and planners, often more so than in others, because the disappearance of the architectural subject from an architecture that continues to exist appears to the architect as a disappearance of self. When looking at something, more than anything, a person will see their own reflection and so for the architect it would be as if looking mirror and not seeing his reflection. ${ }^{18}$ Virilio discusses the same occurrence in the phenomenon picolepsy where we tend to piece together what we know of reality, and cover up what we don't with our own inventions; we refuse to embrace the unknown. ${ }^{19}$ "... The vacancies and absences in perception are assimilated and desingularized into a homogenized and potentially controllable texture of events. The goal of reason is to redistribute methodically the occasional elimination of picnolepsy... to deny to particular absences any active value" ${ }^{20}$ For the architect to recognize the void is to realize and accept the unknown, and while every architect must accept that they inevitably must relinquish their creations to the unknown, to admit

\footnotetext{
${ }^{17}$ Doron. "The Dead Zone and the Architecture of Transgression." p 252

${ }_{18}$ Doron. "The Dead Zone and the Architecture of Transgression." p.258

${ }^{19}$ Virilio. The Aesthetics of Disappearance p.20

${ }^{20}$ Virilio The Aesthetics of Disappearance. p.12
} 


\section{Figure 2.4}

Tacheless, Berlin
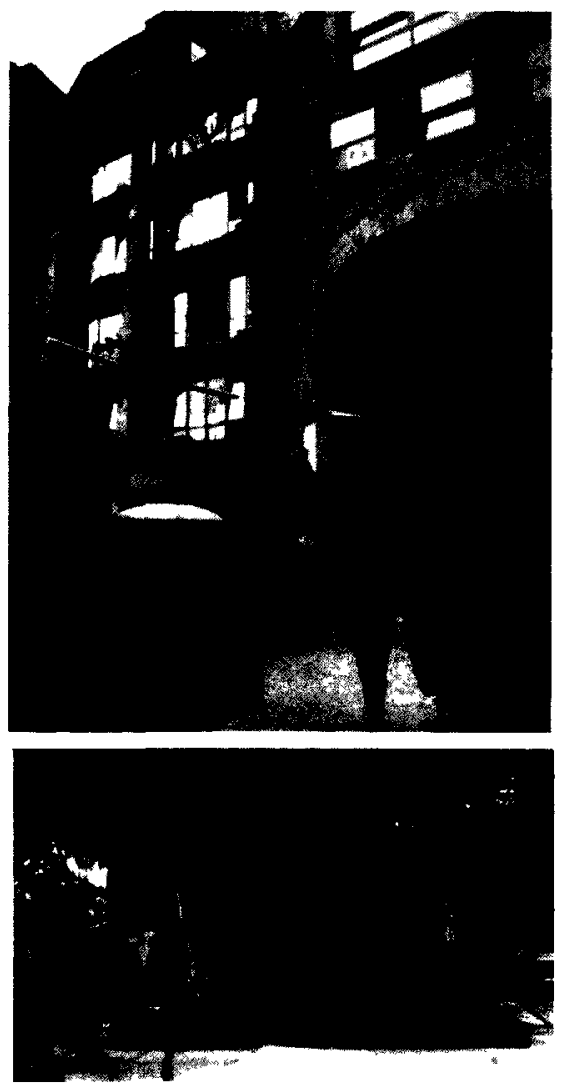

that there exists a system wholly separate from them is, what Doron calls, terrifying. However, to maintain the process of repurposing leftover spaces with the same techniques that created them, because architects refuse to work outside of traditional methods and face the unknown, will never improve the urban fabric. Instead the answer lies within learning from the way marginal communities create their environments and from contemplating the assets of such environments." 21

\section{THE ACT OF TRANSGRESSION I PLAYING WITH BOUNDARIES.}

In reality it is the marginal communities and their informal activities that use the indeterminate quality of leftover spaces to its full potential. They transform the spaces architects and planners see as waste, into places of living, creation and performing ${ }^{22}$ because they understand the potential of the spaces. Furthermore, these communities and their activities often create an environment that is truly their own with nothing more than the means and technologies that are available to anyone. ${ }^{23}$ Everything from buildings to streets and open spaces has potential to them, and are often sites of their influence.

The transformation of a leftover space into one of value by marginal communities occurs through the displacement of many activities that are accepted elsewhere. This act of playing with traditional standards accompanied by the positioning of the leftover space in both a spatial and temporal gap, blurs the boundaries between public/private and interior/exterior ${ }^{24}$ and creates spaces that are needed and wanted but are not provided. Through the activities of the marginalized communities failures in the architecture of the urban fabric are discovered and remedied, and it is to their techniques that architects and planners should be looking instead of eradicating. ${ }^{25}$

\footnotetext{
${ }_{21}^{21}$ Doron. "The Dead Zone and the Architecture of Transgression." p.252 ${ }^{22}$ Doron. "The Dead Zone and the Architecture of Transgression." p.253

${ }^{24}$ Doron. "The Dead Zone and the Architecture of Transgression " p 253

25 "The Dead Zone and the Architecture of Transgression." p.254

${ }^{25}$ Doron "The Dead Zone and the Architecture of Transgression." p.255
} 
The old fashioned and cast off are rescued by the child and reassembled in his or her own world in miniature. The demolition site, the space where the old is torn down to make way for the new is transformed into a site for playful reconstruction. The child gathers up and saves the fragments found in the modern metropolis and

reassembles them in new constellations.

-Graeme Gilloch, Myth and Metropolis Walter Benjamin and the City 
Johan Huizinga, the cultural historian who discussed play as the formative elements in creating culture, began his book Homo Ludens with 'play is older than culture. ${ }^{26}$ Therefore, any definition that used terms produced from culture, such as logic, biology, or beauty, were inadequate to define it. Instead, the concept of play could only be understood through its specific qualities. ${ }^{27}$ After a comparative analysis of the qualities identified by Huizinga with those proposed by Richard Sennett, a writer who re-examined the concept of play while proposing a different way of looking at the public domain in his book The Fall of Public Man, play can be described as: a voluntary activity that is accompanied by good feelings, distinct from everyday life and done for its own sake. It is carried out in a time and space of its own, separate from other activities and protected by the rules. These rules define and advance the game yet they also provide a flexible framework in which play can grow.

Together these qualities, derived from both Huizinga and Sennett, compose a comprehensive overview of the nature of play; the most fundamental of these is that play is free. Play is no longer play if the player does not volunteer to do it. It becomes a chore like any other activity that is forced upon the unwilling. For this reason, play must always invoke good feelings. The moment playing does not make the player feel good the player will not wish to continue and it is no longer play. It has become work and so the game is stopped and play ends. Play, as a voluntary act, also allows for the flexibility to commence or terminate at will. This suggests that the physical act of play occupies a place within its own, separate, time and space. With no regard to the ordinary world, this place can be constructed or deconstructed at the will of the player regardless of their present physical location. Furthermore because play preceded culture, it has no cultural end in the ordinary world. It is not a tool for the acquisition of societal skills. Instead play has its own meaning, course and rules which are separate from the ordinary and thus increase the player's detachment. However, while this separation from the ordinary often results in make believe or pretending,

\footnotetext{
${ }^{26}$ Huizinga Homo Ludens. p. 1

${ }^{27}$ Huizinga Homo Ludens. p 7
} 


\section{Figure 3.0}

F\# Major Scales. The rules pertaning to scales and notes are essential to playing music
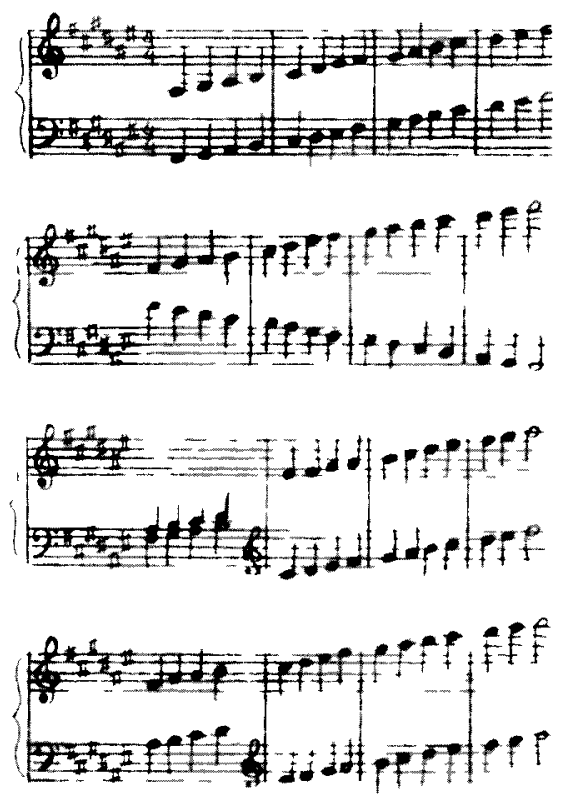

this does not designate play to be trivial. Play often proceeds with the utmost seriousness. ${ }^{28}$ This seriousness is most palpable through the rules and play would not exist without them. Evidence attesting to this is the reaction of children when one of them is suspected of cheating in a game. To break the rules is a grave offense as it puts the sacred and fragile play world at risk of falling apart. The play world needs the definition and protection of the rules. ${ }^{29}$ It is in the characteristics of the rules of play, specifically their ability to shape both the act and the space in which the act is performed, where the interest of this thesis lies.

\section{THE RULES OF PLAY | THE TOOLS OF A CHILD}

According to Huizinga, all play has rules and they serve many critical functions to the act. Because play is a voluntary activity, they must be freely accepted but are henceforth binding, allow no doubt and determine what 'holds' in the temporary world circumscribed by play. ${ }^{30} \mathrm{He}$ further states that as soon as the rules are broken the whole play world collapses. The game is over and the spoil-sport has shattered the play-world itself. ${ }^{31}$ Yet within this rigid structure lays a hidden fluidity. Play, like other activities such as music or poetry, exists "with binding rules but ones that allow infinite variations."32 Thus the game that is created and protected by the rules is simultaneously progressed by them; specifically through their malleability. The malleable quality of the rules is what creates the environment in which play flourishes. The structure provided by the rules allows for creative interpretation and even alteration during play. Unlike breaking the rules, an alteration to them does not terminate play because each alteration made reflects the desires of the all players and is thus unanimously agreed upon. In this way, the rules are not broken, and the game progresses intact. Therefore, children in play are not confined to specific acts by 
the rules; instead they retain the ability to discover new ways of doing things withın the structure of play through their aptitude to recalibrate the rules. While offering freedom to the act of play, the modification of rules can also be used to provide children with the opportunity to pursue the desire of continuing to play by changing rules specifically to prolong the game. ${ }^{33}$ Sennett concludes that, "the tools which permit children to delay, to remain in a state of play, are the rules." 34

Often rules and stipulations are intentionally constructed to delay winning because victory is only the justification of the game, not the game itself. It is all the acts that leads up to winning that compose play and to win is to end the play. Manipulating the rules to prolong the game creates a condition Sennett refers to as a diminished consciousness of self, or a detachment of self. ${ }^{35}$ it is this condition that provides a child who is playing the opportunity to dismiss his ordinary identity and competitive desires to win in order to play; whether that means becoming another being entirely or simply creating or accepting rules that hinder him to allow the game to continue. Sennett writes that "when small children are put with older children and asked to play... the older children immediately decide to change the rules so that the little ones will not be elıminated." ${ }^{36}$ During the act of play, rules are frequently negotiated amongst players to achieve equilibrium between them and thus extend the game. It is by altering the rules to control the inequalities amongst players, that children learn a control over their impulses for immediate gratification that can be detrimental to the game. An achievement of a detachment of the self in order to accept the rules and an interest in what they mean and provide allows chıldren to fully grasp what it means to play.

Once outside the realm of a child, however, rarely is there acceptance of rules that delay winning and the concepts of recalibration and alteration are no longer associated with the definition of rules. They are instead static, rigidly restricting the potential for the play they once structured. Furthermore the social

\footnotetext{
${ }^{33}$ Sennett, Richard The Fall of Public Man New York Vintage Books, 1978 p 317

${ }^{34}$ Sennett The Fall of Public Man p 318

35 Sennett

${ }^{36}$ Sennett The Fall of Public Man p 319
} 
bond that Sennett says is created from altering the rules ${ }^{37}$ disappears with the disappearance of play. Children acquire social skills and the ability to accommodate others through rule manipulation. Instead, rules become used to exclude potential players and pose one against another, rather than adjusted to incorporate everyone. In the adult world only modes such as poetry and music remain as the last strong hold of play ${ }^{38}$ because the rules are still understood as being firm but allowing for infinite variations within.

Figure 3.1

Scenes from Finding Nevertand With just a little bit of imagination, I can turn around and see
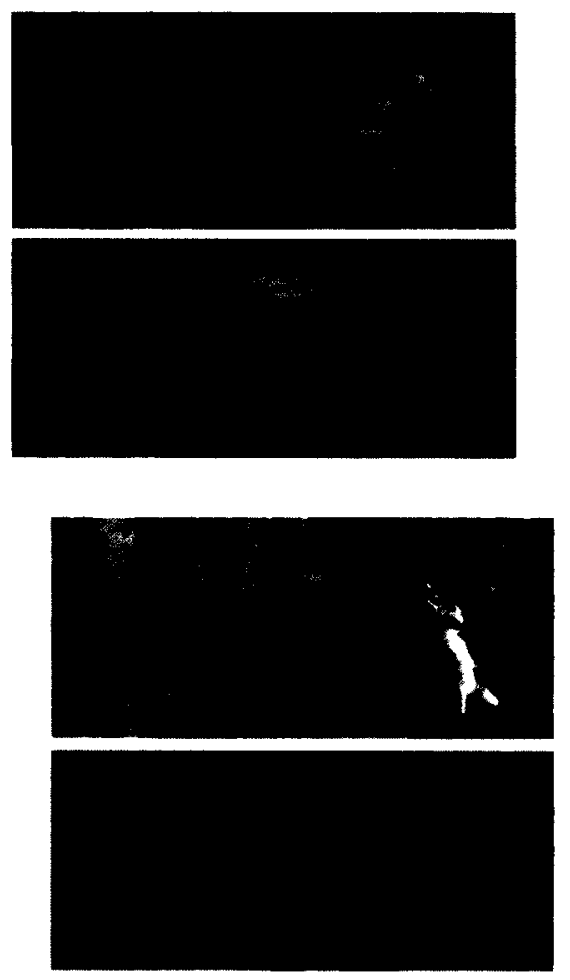

\section{PLAYGROUND I EPHEMERAL PERFECTION}

It is through the flexibility of the rules that play can manifest and proceed. However, while influencing play, they also influence the world in which play takes place. All play has its being in a playground. Huizinga describes playgrounds as marked out, ephemeral worlds which are isolated, governed by the moment and ruled by their own logic which transcends the logic of the ordınary. ${ }^{39}$ Playgrounds emerge in response to a desire to play, and can therefore materialize anywhere. Writer Susan Linn, a professor of psychiatry who has written extensively about play therapy, writes in her book, The Case for Make Believe, that the early stages of play are founded on the ability to create worlds that no one else can see. ${ }^{40}$ She continues by explaining that these worlds are created by a child's capacity to simultaneously recognize an object for what it is and what it could be. Once they realize this capacity, they are able to alter the world around them to play out their desires. ${ }^{41}$

The tools available to children, aiding them in creating these worlds, are the rules of play. Without the rules there is no play, nor is there a realm for the play to occur in. According to Linn, "play thrives in the intersection between the inner world of fantasy and inner experience and the external world that exists in

\footnotetext{
${ }^{37}$ Sennett The Fall of Public Man $\mathrm{p} 319$

${ }^{38}$ Hulzinga Homo Ludens p 132

${ }^{39}$ Hulzinga Homo Ludens p 129

${ }_{40}$ Linn, Susan The Case for Make Believe New York The New Press, 2007 p 17

${ }^{41}$ Linn The Case for Make Believe p 18
} 
time and space... it exists neither wholly in the inner nor wholly in the outer - but it can shape both." ${ }^{42}$ It is here where playgrounds reside, influenced by the physical and temporal reality of the world, but distinctly separate from it. This separation is caused by the rules. Sennett proposes that "it is only by erecting rules that the children keep themselves free of the outside, non-play world. The more complicated the rules are, the longer the children are free." ${ }^{43}$

In governing play, the rules simultaneously distinguish the game from reality and construct its playground. In creating this isolation, a playground becomes unconfined by the constraints of the ordinary and its rules are free to introduce a different condition of time and space on it. This separation coupled with the inherent ability of the rules to constantly adapt to the desires of the players, causes a playground to exist in a continually evolving present. During this temporal existence, a playground offers the players exactly what they need. Huizinga writes that the rules create a perfectly ordered place that exists temporarily in the confusing world that is reality. ${ }^{44}$ The malleability of the rules allows for the playground to perfectly respond to desires of the players.

This condition is similar to the temporal gap that is experienced by leftover spaces which causes its indeterminate quality. Yet, while the techniques children employ to create their playgrounds and their capacity to see potential in their surroundings could be used to improve methods used by urban planning they are ignored. Huizinga writes that as culture proceeds and becomes more complex, the old cultural soil, once communicative with play, is gradually smothered under layers of modern ideas and knowledge which have lost touch with it. Thus play recedes into the background. ${ }^{45}$ With this recession comes little drive to create playgrounds out of the opportunities in daily life. The rules outside play and playgrounds remain fixed, though this need not be the case. According to Huizinga, the arena, the card table, the magic circle, the temple, the stage, the screen, the tennis court, the court of justice etc. are all in form and

\footnotetext{
${ }^{42}$ Linn The Case for Make Believe p 12

${ }^{43}$ Sennett The Fall of Public Man p 318

${ }^{44}$ Huizinga Homo Ludens p 10

${ }^{45}$ Hulzinga Homo Ludens p. 46
} 
function playgrounds, because fundamentally, playgrounds are dedicated to play - the performance of an act part, ${ }^{46}$ and all of these places have potential to do that.

${ }^{46}$ Huizinga Homo Ludens $p 10$ 
In the meantime gaps exist-vacant plots, ground behind retail strips, abandoned buildings This inventory does not build a bleak topography of absence or philosophy of loss but coincides with a belief that meaning occurs in these spatial interruptions in the trajectory of capital and economic vectors that form the cityscape There is a whole world of spaces left behınd without official programme or function that the practices discussed set out to expose

-Hilary Powell Recycing Junkspace findıng space for playtıme in the city 
Baudelaire's notion, "countless layers of idea, images, feelings have fallen successively on your brain as softly as light. It seems that each buries the preceding, but none has really perished" 47 captures Huizinga's lament on the loss of play in culture. While the capacity to play exists in every person, over time it is buried and forgotten. As the layers increase, the detachment from play grows and soon it is replaced by rigid rules and a hesitation to stray from them. This hesitation is why architects try to solve leftover spaces using the techniques that originally created them. Gaps are filled with the traditionally 'useful' functions that time after time prove inadequate to consume the space, further producing 'wasted' space as seen in the Underpass. When architects look at these spaces they see what they perceive to be a foreign order. This order must be changed so that it can amalgamate and contribute to the ordinary. However, the system governing these spaces, though different, is not foreign, it is only forgotten. Rather than looking at these spaces with eyes that see them as opposite to the built environment, architects instead need to see the spaces with the eyes of a child who sees them as sites of playful reconstruction. $^{48}$

Because of their inherent qualities, leftover spaces possess the ability to spark the imagination of users and invite them to play. The act of users entering a leftover space and re-purposing it for the duration of their stay is the same act a child performs when creating a playground amidst the everyday world and proceeding to play. An indeterminate leftover space is, by its nature, a temporary world within the ordinary because of its in-between existence. Its lack of permanence and rigid structure provide visitors within its boundaries the opportunity to impose on it their own set of governing rules, temporarily transforming the space like a child does with his play. Linn observes that when children are free to play, objects around them can go effortlessly from one function to the next, as demonstrated by two kindergarten girls playing

\footnotetext{
${ }^{47}$ Virilio. The Aesthetics of Disappearance. p.39

${ }^{48}$ Powell. "Recycling Junkspace finding space for 'playtıme' in the clty " $p 88$
} 

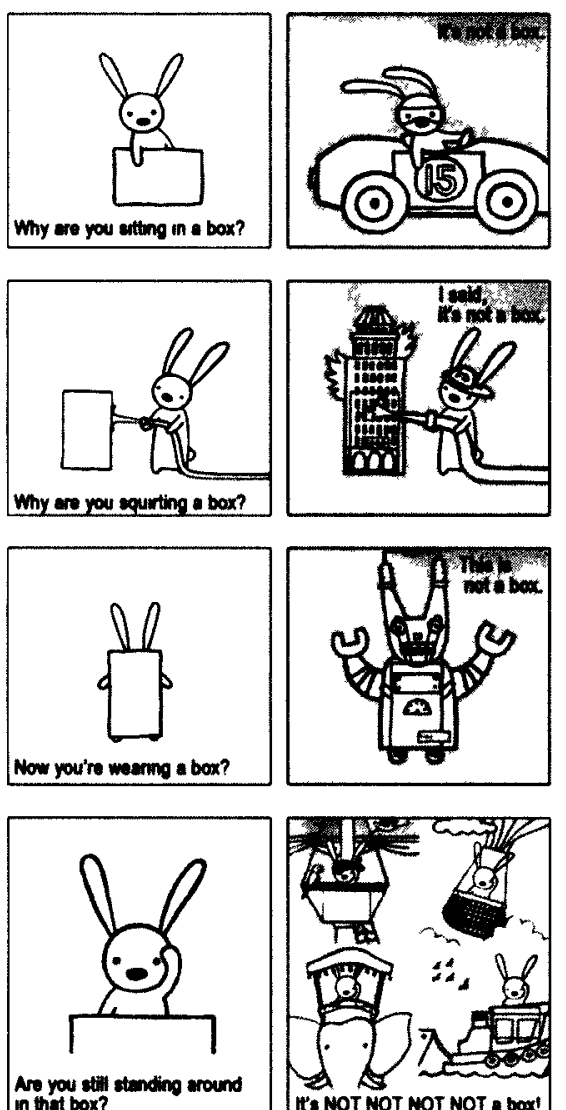

Ave you cotil
in that box?

Figure 4.0

Select pages from Antoinette Portis's Not A Box with a hat, fluently transforming it from a dangerous weapon to a cradle. ${ }^{49}$ When performed, this act of translation succeeds in detaching objects and spaces from the ordinary world and converting them into playgrounds. This transformation, specifically of a leftover becoming a playground through the acts of users, is what architecture must facilitate if it is to successfully inhabit the space. To further support indeterminacy, it must embody the child's capacity to see objects and spaces for what they are and what they could be. In play, a child expresses this ability through the establishment of rules and the construction of a playground; the hat is no longer just a hat, it is a weapon used to kill bad guys in the kingdom. For architecture to exemplify this ability, it too must look to do it through the rules.

Within a playground the rules of play are the governing order and they are what distinguish it from the acts and limitations of the ordinary. Similarly, a place of indeterminacy naturally invokes play in users because of its alternative governing order. Therefore the architecture that can inhabit these spaces must simulate the framework created by a player's rules and materialize it as a set of physical rules for the site that promotes its existing alternative order. These 'architectural rules', like those of play, are completely accepted, yet adaptive to the users' desires. The forms created for leftover spaces must serve the main functions that occupy it, but in their absence this architecture must be indeterminate itself; able to adapt to each temporal function that materializes prior to, in-between or after those that frequently inhabit it.

The way children manipulate the rules when playing and the way they see potential and transform their surroundings, presents architecture with a way to escape the progression of Koolhaas's Junkspace, and the cyclic creation of determinate leftover spaces. Rather than relying on determinacy and traditionally rigid rules, architecture can adapt techniques observed in play, particularly imaginative rule alteration, to learn to embrace the indeterminate potentials of leftovers. By designing architecture around the concepts which naturally fall under play, namely participation, expression and adaptability, it will possess what it needs to recalibrate the standards dictating the form and function of a 'useful' space and promote

${ }^{49}$ Linn The Case for Make Believe p 21 
leftovers as valuable assets to the urban fabric. To a child who sees potential in everything, there is no waste - a box is every bit the toy that the item inside is. Therefore the process of designing according to play avoids the perpetual creation of leftovers and the neglect of indeterminate potentials by equipping architecture with the ability to wholly respond to these spaces, celebrate their inherent potentials and promote visitors to use them.

\section{JOINING THE GAME I APPROACH TO UNDERSTANDING LEFTOVER SPACES}

Designing architecture for a leftover space that mimics the rules children use to play requires a different understanding of space and what architecture can do for it. The framework of a playground is constructed with the rules of the game. Likewise, a leftover space is also founded upon a series of embedded rules prescribed by factors such as weather, geographic formation, surrounding environment and urban connections. The understanding of space as having inherent rules is fundamental to the implementation of architecture into a leftover space. A set of rules, which is unique to each space, influences every aspect of the site, from its form to its potential use; they are what entice various programs and users to inhabit spaces. Therefore, these rules must be understood and rigorously deliberated in order for an installation to properly support and encourage the existing leftover condition. The rules compose the core of the space and are the guides to whom the architectural installations must respond if they are to enhance these spaces instead of merely creating and erasing them.

To strategically uncover these rules and the resulting potential they create for programs searching for refuge, techniques such as recorded visits, historical research and user interviews and surveys are employed. Frequent recorded visits, which are conducted to observe the occurrences and condition of the 


\section{Figure 4.1}

Web of activities and their desires.

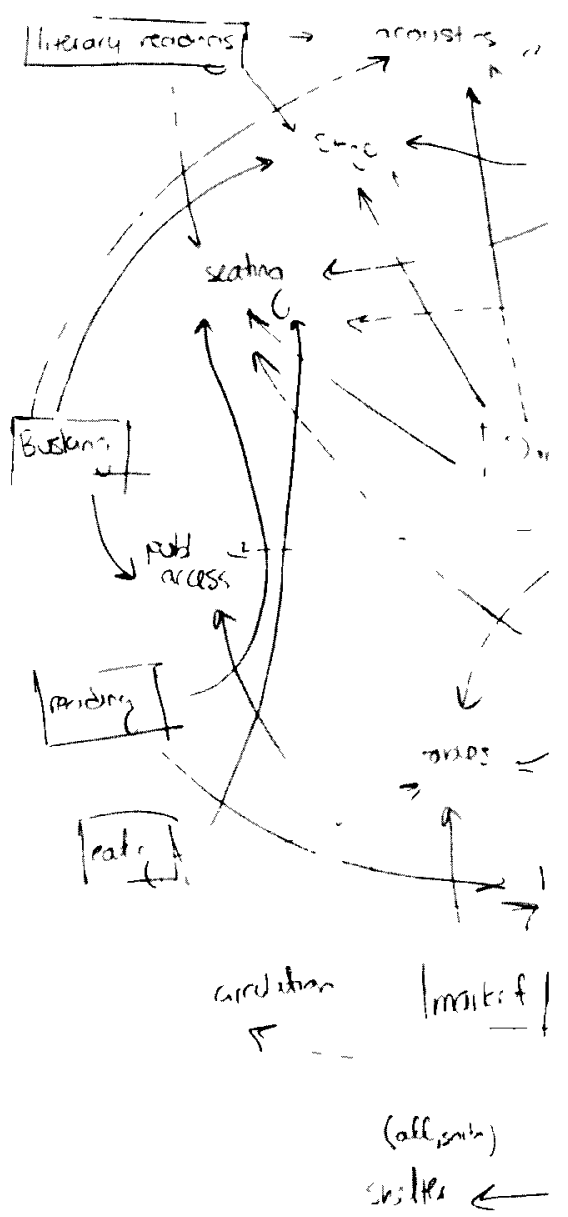

site, create a comprehensive knowledge of the space and uncover its inherent potentials. The records are documented with a procedure which involves notes on the date, time, temperature, weather conditions and duration of stay, to establish consistency among the entries and give reference to any noticeable changes. The inherent rules of the space reveal themselves most clearly through the activities that occupy them. The studio of Atelier Bow-Wow in Tokyo calls this exercise 'people practicing their own space production. ${ }^{50}$ In this studio members act as urban detectives, intently studying the behaviour of the city and people in order to appropriately embrace leftover spaces and design for the activities that genuinely materialize there. The activities that have an impact on a space include both those that are pronounced in their occupancy and those that subtly and fleetingly inhabit the space, leaving only evidence behind from previous fruitions, such as garbage or footprints. The reason for the briefness of their tenure is often due to their marginal nature. The regulations imposed on a space concerning informal activity are very strict and affect the way the marginal community, in particular, use it. Over time, many learn to operate within the limits of these impositions while still trying to embrace the full potential in the site, and it is their behaviour that continues to indicate most directly the ingrained rules of the space and where its hidden potentials lay.

It is these inherent rules of a site that produce the potentials for activities to emerge. The desires an activity possesses regarding its ideal environment respond to the rules of a space - assessing them and deciding whether the space satisfies enough of these desires to sustain the venture. This act is continually done, often subconsciously, by users when they are attempting to find the perfect spot to read, eat, play soccer, etc. Sunlight, terrain, visibility, ambient noise, etc. are part of the rules a space is built upon. However, the articulation of these rules is not the same for each space and it is necessary to revise traditional presumptions of what these elements mean to a space. In an interview, Yoshiharu Tsukamoto,

\footnotetext{
${ }^{50}$ White. Mason. "Atelier Bow-Wow. Tokyo Anatomy." Archinect. Features Article 56468. 2007. Accessed May 2011. URL: http://archinect.com/features/article/56468/atelier-bow-wow-tokyo-anatomy p.2
} 
founder of Atelier Bow-Wow, said "in such small sites, it is important to revise your understanding of what a view is. If we keep to the traditional understanding of view, we cannot make a window on the site."

The alternative way of understanding space as being founded on rules must be accompanied with the realization that even these rules can be finessed by the implemented architecture as it provides the users with what they want in order to simultaneously invite them to play with their surroundings. The architectural rules created to promote leftover spaces must embody the rules of the space, while also playing with these rules and suggesting to users possible manipulations; otherwise these installations are no different from the rest of the built environment. Just as children creatively adapt the rules of their play to suit the needs of the players, architectural rules must also display the same level of ingenuity both in their ability to provide for the users, and in the methods used to achieve this goal. The capacity to adapt to users' desires is not enough if the architecture itself does not spark the imagination. The architecture proposed needs to inspire users to play. For this to occur it must be playful in its approach of offering the users their needs. The World Design Park Complex project proposed by Steven Holl Architects in Seoul, South Korea is an example of this in its efforts to fuse architecture and urbanism together. ${ }^{52}$ The project immediately begins to play with the rules of what a landscape in an urban setting should be. The design pivots a section of the proposed scheme upwards by ninety degrees to create a vertical park which extends storeys above grade. This simple change in orientation transforms a traditional park into a unique experience while still maintaining the essence of a green urban landscape. Furthermore, the continuation of the landscape from the horizontal to the vertical dissolves the boundary between the two, allowing for the user's imagination to ponder the possibilities the form has to offer.

\footnotetext{
${ }^{51}$ White. "Atelier Bow-Wow: Tokyo Anatomy." p. 10

${ }^{52}$ Steven Holl Architects. "The World Design Park Complex." www. stevenholl.com. 2007. Accessed Jan 2011. URL http://www. stevenholl.com/project-detail.php?type=masterplans\&id=99\&page=1
} 


\section{INSPIRING PLAY | THE TECTONICS OF A PLAYGROUND}

\section{Figure 4.2}

Landhausplatz, Innsbruck.

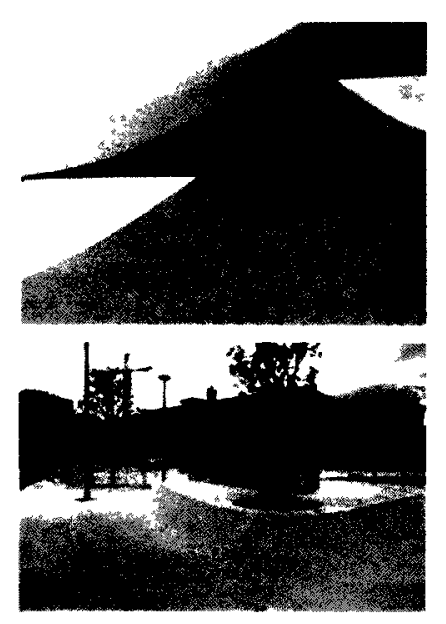

Figure 4.3

Holl's World Design Park Complex concept sketch

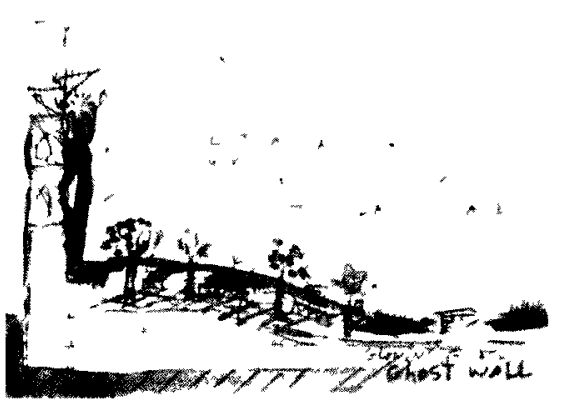

The continuation of the landscape from horizontal to vertical in the Park Complex suggests the importance materiality has on inspiring play. The selection and application of materials is a very powerful catalyst in architecture's ability to stimulate the imagination. The terrain in Holl's project is perceived as a continuous material - adapting throughout the site over various orientations and forms and eliminating the visual boundaries created by different converging materials. The cusp of one material creates a visual cue that proposes that an activity should terminate there as well. With a single, continuous material adapted throughout an entire space, there is no space fragmentation because this visual boundary does not exist. A playground is thus free to occupy as much of the space as the player pleases without being imposed upon by material barriers. Landhausplatz by Stiefel-Kramer Architecture in Innsbruck, Austria is a project that looks at adapting a single material throughout the site to create this condition. Poured concrete is molded over a series of forms that gradually rise and fall, producing minimal boundaries that dictate where one program should end and another begins. A place considered by one to be for reading, for example, is thought by others to be for performances. Likewise, a place thought to be used for formal activities also has the potential for informal activities. The technique of one continuous material used throughout creates a space that is physically and visually indeterminate.

Yet while the use of one material provides an indeterminate space that has destroyed the demarcations that limits a person's playground from freely expanding and contracting as desired, the single material used to create this space also needs to excite the user's imagination. A transformation of that one material by way of various treatment and application processes can further the impact it has on users and their imagination. By applying a single material in a variety of ways and temporarily suspending the preconceived material conventions, the inhabitant of a space is alerted to the diverse potentials one object can have, an effect similar to what one would feel in a leftover space where 


\section{Figure 4.4}

Stone colonnades, Parc Guell, Barcelona
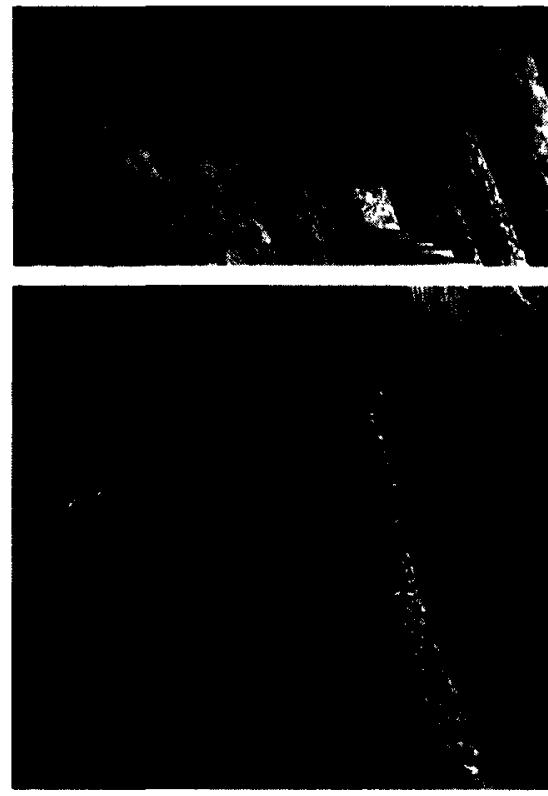

Figure 4.5

Ceramıc mosaıc, Parc Guell, Barcelona

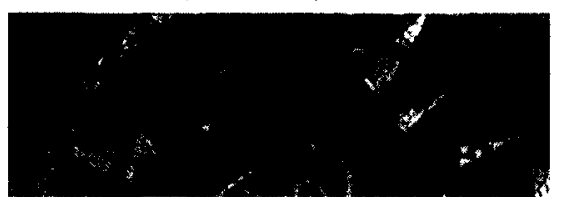

architecture has been added to promote its various inherent potentials. Furthermore, in addition to manifesting the concept of infinite potentials within one object, many materials that are associated with processes that generate leftovers can further challenge the standards concerning what is 'useable' through innovative application methods, whether it is using the pieces deemed to be waste or reusing elements that are no longer suitable for their intended purpose. Antonio Gaudi's Parc Güell is a project that incorporates leftover materials in creative ways whıch speak to the imagination. To add colour and vibrancy to his work, Gaudi often used mosaics, a technique which utilizes broken ceramics and glass. In this project, the ceiling of the park's lower section and the bench above are surfaced with magnificent mosaics, fabricated from both materials Gaudi broke hımself, as well as broken plates, cups and vinegar bottles that were acquired from his friends. ${ }^{53}$ For other elements of the project, leftover stone excavated during the construction of the park was used to create some of the most fantastic forms in architecture. Covered in this stone was his solution for the flying buttress - an organic wave-like form supported by an inclined colonnade of stone trees used, in this case, to support the viaduct beside the main terrace and maintain the shape of the mountain upon which the park is built. ${ }^{54}$

Gaudi's use of stone is of particular interest because it unlocks the many potentials in a material so hugely associated with leftovers in a way that few architects have done before or since. The acquisition of stone typically creates more waste than 'useable' product as seen with the example of slate, where every ton of product produces thirty tons of waste. ${ }^{55}$ However, through creative application techniques (dry stone, mosaics, gabions etc.) much of this material typically deemed to be waste is not; much like a leftover space itself.

\footnotetext{
${ }^{53}$ Núnez, Juan Morell "Gaudı and the Catalan Craftsmen of His Tıme "Living Gaudı New York Rızzolı, 2002 p 92

${ }^{54}$ Solé, Eduard "The Park Guell (1900 -1914) "Gaudı and Barcelona Club Accessed May 2011 URL

http //www gaudiclub com/ingles/I vida/park asp

55 Gagne, Norm Sales Supervisor for Merkley Buildıng Supply Ltd Personal Interview Sept 212010
} 
Although these places and the terms which are used to describe them have been a popular subject in the planning and architecture discourse, there has been little genuine examination of these places; ... what is basic to any objective research, and the practice of planning still claims to be such is the question of whether the terms 'Dead Zone', 'wasteland', 'void' etc. adequately describe these place, which has never been raised.

-Gill Doron, The Dead Zone and the Architecture of Transgression 


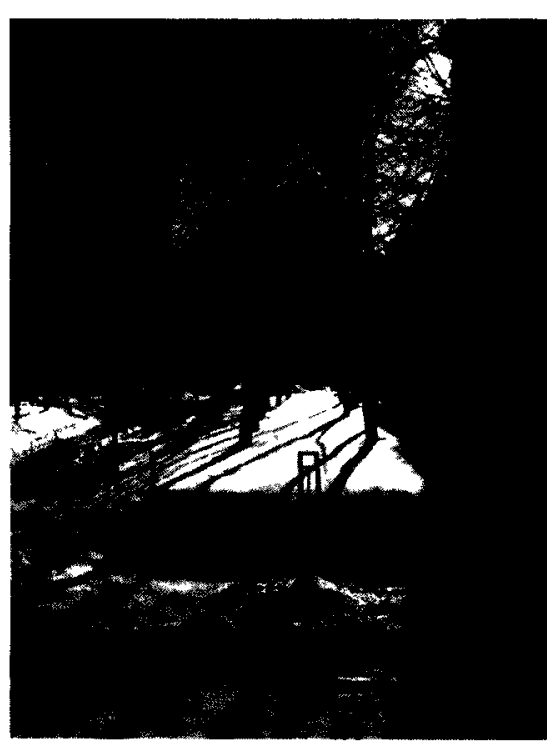

Figure $\mathbf{5 . 0}$

The Underpass: The Leftover's Leftovers.

Before its current configuration, the Underpass was originally home to a hotel that was connected to the Union Train Station when it opened in 1912. In 1966 the closure of the train station, upheaval of the tracks and extension of Colonel By Drive created the Underpass as it exists today. ${ }^{56}$ Along with the designation of Colonel By Drive as a promenade along the canal came the desire for a more efficient traffic connection between it and Rideau Street. With the improvement of automotive traffic being the main consideration, the ramp from Rideau Street was built despite the formation's inability to allow for a street level walkway. In order to complete the pedestrian link, a path was sunk beneath the road, leaving pedestrians to feel inferior to the automobile. And while the redefining of this leftover space into a walkway immediately solved the issue of the missing pedestrian link, there was little thought given to the site as a whole and what its potentials were. The areas which did not contribute to this function became leftover once again, scattered throughout the site. In an attempt to unite some of these fragments and capitalize on some of the space's inherent potentials, the Terry Fox Statue was situated on the eastern portion of the site, acting as a destination point for visitors and utilizing the Underpass's size, public location and exposure. However, despite the appropriateness of this space, the statue was recently relocated to Wellington Street, across from the Parliament, where it has been designated the beginning of the Path of Heroes. This is a route which tours Ottawa and Hull, passing by statues which commemorate the monumental achievements of Canadians throughout history including the War Memorial, the Tomb of the Unknown Soldier and the National Peacekeeping Monument. While the Underpass sits along this path, as is the case with many other local experiences, it has no contribution to offer and therefore remains merely a pedestrian walkway for those traveling to the Rideau Centre or the Byward Market, though there is great potential for it to be more.

${ }^{56}$ Cormeir, Nick. Personal Interview. 25 Oct. 2010. 
AN URBAN JOINT | A GATEWAY BETWEEN THE FORMAL AND THE INFORMAL.

Much of the Underpass's potential can be credited to the position the Underpass holds in the urban fabric. Within the city, the Underpass finds itself situated not only along the Path of Heroes but at the joint between two major downtown sections of Ottawa. It is the primary pedestrian link between the city's western financial core and its eastern arts and theatre district. This link is amplified by the Underpass's location on the southern side of Rideau Street, at its junction with Colonel By Drive. This position alone designates the Underpass to be the most direct and almost unavoidable pedestrian route through the city, as the river which lies just north dictates that most traffic approaches from the south. In addition to the Underpass's position as an urban joint its proximity to the former Union Train Station, the Chateau Laurier and other arrival points convert it into a gateway for the city.

It is this particular potential that is most appealing to those searching to give the Underpass a more formal purpose. The Downtown Rideau Business Improvement Area (DRBIA), a group responsible for the upkeep of the Rideau Street district, looks to the Underpass to act as the entrance to the newly deemed Arts and Culture Center of Ottawa ${ }^{57}$ located along Rideau Street. The group has formally repurposed the space to host performance previews, art displays and craft markets in order to inform the public of events and promote the activities which occur in this arts district. In an attempt to better serve this gateway function, renovations on the Underpass were conducted and completed in 2009. The new renovation is composed of a variety of unique spatial experiences that weave under and surround the Rideau Street automotive connection to Colonel By Drive. The DRBIA has identified nine distinct areas or elements that comprise the formation of the site and noticeably contribute to its urban context. ${ }^{58}$ The layout of this space was intended to allow the fragments to act either on their own or collaboratively, depending on the use.

\footnotetext{
${ }^{57}$ The Downtown Rideau Business Improvement Area "Call to Local Artısts." 2010 The Underpass pdf. April 9, 2010. p.1 ${ }^{58}$ The Downtown Rideau Business Improvement Area "Call to Local Artısts "Appendix B, p.6
} 
The nine sections are as follows:

Platform I Fence I Trees

Circle I Catwalk I Ledge I Ramp

Wall I Path

For the purpose of this thesis, these features are further grouped together. The West Side of the site is composed of the platform, the trees and the path. The ledge, the circle and the ramp compose the East Side while the wall, the fence and the catwalk make up the Covered Section: the wall and the fence are located underneath the road and the catwalk runs along it, adding to the covering.

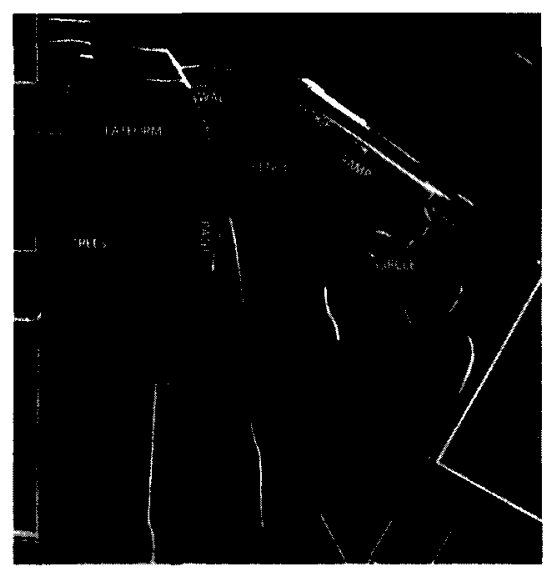

Figure 5.1

Labeled Site Model

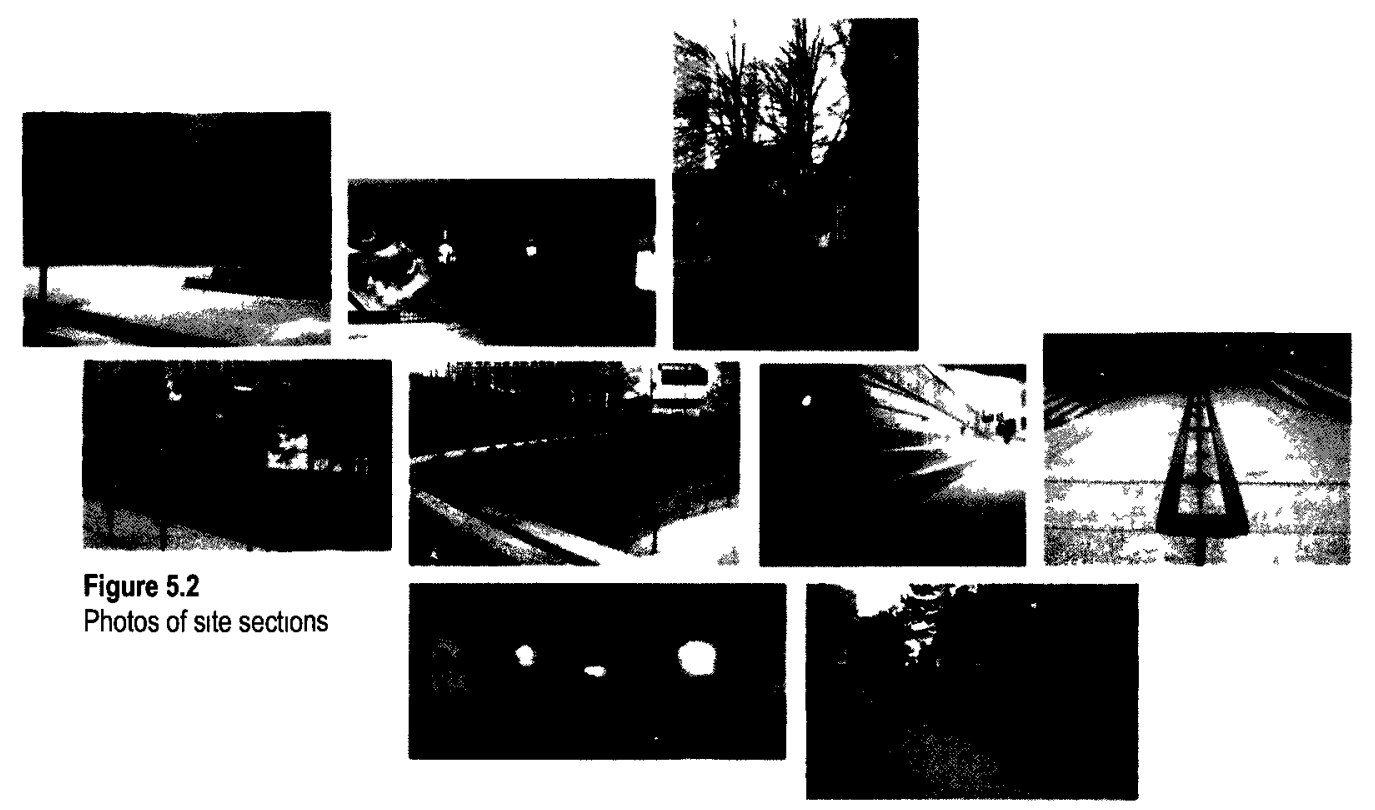


The renovation, however, had another effect on the usage of the Underpass. While converting the space into Ottawa's Culture Centre gateway, the DRBIA was simultaneously attempting to eradicate the potential for informal uses and evict the marginal community who, until recently, were the primary users. Due to the combination of its subterranean position and architectural features, in their attempt to find refuge, street dwellers found in the Underpass a place to live, sleep, meet and busk. Different from the approach of the DRBIA, their use of the space responded directly to the capabilities of the site and indicated not only the type of the activities which naturally materialize and where they preferred to manifest, but also what needed to be improved in order to inspire usage in other areas.

Many of the uses by the marginal community also suggested that there was not only a physical connection between the Underpass and its surrounding urban fabric, but also a social connection made palpable through the relationships of its users. While leftover spaces exist physically disconnected throughout the city, these spaces are in fact linked by the relationships users form with the space and with each other. Before the redesign and implementation of a new set of rules, the Underpass was one of the marginal community's key congregating areas. As one of Ottawa's largest urban leftover spaces, it offered shelter with enough room to gather. ${ }^{59}$ Through the displacement of traditionally private activities to public indeterminate spaces throughout the city, when combined, these sites created a form of urban house with leftover spaces for rooms and streets for hallways; a place to live in rather than pass through. $^{60}$

Now, however, the informal is excluded from the Underpass and, similar to the way the relationships of the marginal community connects it to other leftover spaces, the negative attitudes authorities harbour towards the space also serves as a link. The processes used to prevent informal occupancy can be seen replicated throughout leftover spaces around city. The conditions leftover spaces are reduced to by the

\footnotetext{
59 "Ottawa's Homeless Fight for Right to Sleep in Underpass." CBC News. 31 Jan. 2008. Accessed: Oct. 2010. URL:

http://www.cbc.ca/news/canada/ottawa/story/2008/01/31/ot-homeless-080131.html\#ixzz11Uu2lng1

${ }^{60}$ Doron. "The Dead Zone and the Architecture of Transgression." p254
} 
formal community - fenced up, under surveillance and serving a determinate function that under uses the site, further creates a link between them. The Underpass experienced this attitude, like many before it, when the general uneasiness and concern for safety in this area erupted after a controversial encounter and resulted in an outcry for change. ${ }^{61}$ The city immediately took action by adding a fence, lights, cameras, and speakers playing music to prevent sleepıng, loitering and busking. The objective was to improve the space, however, the eradication of the marginal community resulted in denying the space of those who actively inhabit it and respond to the its natural set of rules. Furthermore, the ensuing renovation, intended to convert the space into a 'proper' gateway, does not succeed because the final design was based more upon the insistence of removing the informal rather than the realization of the space's inherent rules or potentials. Thus the site remains almost exclusively a pedestrian link as its innate rules are largely ignored and its potentials are unable to flourish.

\section{PRE-EXISTING CONDITIONS I THE RULEBOOK}

To succeed in creating an architectural design that allows the Underpass to reach its potential, the space must first be rigorously understood by way of its embedded rules and then made to respond to them. Currently, many of the activities inhabiting the space are ones the DRBIA deem appropriate to promote Rideau's arts and culture district and not the ones the space is inherently suited for. By promoting one set of activities over another, as in the case of the gateway program repressing the informal, the full potential of the site is suppressed and cannot be achieved. The current design has exclusively focused on the specific desires of a few users rather than the overall abilities of the site resulting in the space experiencing an uneven distribution of use; some areas are congested with conflicting activities and other areas are left empty and neglected. Instead of repurposing the site to satisfy a superimposed function, the renovation of the Underpass must support the intrinsic set of rules which stem from the condition of the

${ }^{61}$ Seymour, A "Hankey acquitted in Ottawa underpass stabbıng " The Ottawa Citizen 7 Nov 2008 Accessed 29 Nov 2010 URL http //www canada com/ottawacitizen/news/story htm/?Id=9afe0fc9-a86f-4b0b-8828-a84b5b3addd7 
Figure 5.3

Diagram of Location of Existing Activities.

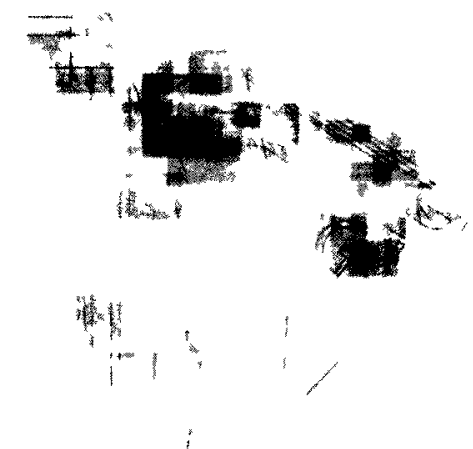

Figure 5.4

Current Traffic Patterns.

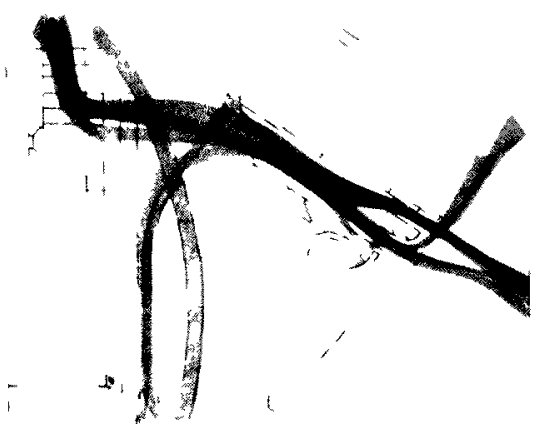

space. Furthermore, coinciding with the discovery of the space's rules, it is here where many notions of play can be applied. While the application of an architectural intervention into the Underpass must respond to its innate rules, if it is to succeed in engaging the entire space, the process of creatively manipulating the rules to achieve the desired conditions for a range of activities is necessary.

In the case of the Underpass, the most prominent of these rules are those that pertain to the program of a pedestrian walkway. Regardless of the other potentials the site may boast because of its situation, composition or geographical position, its bridging location in the urban fabric requires the Underpass to fulfill the role of a pedestrian link. In addition, the rules concerning traffic flow are among the primary rules that must be observed when understanding the space as there are many accompanying conditions which greatly impact the emergence of other activities on the site. The effects of the public exposure associated with a highly used pedestrian street were underestimated at the time of the previous renovation.

While the potentials that arise from this public exposure are acknowledged in the design by the placement of the current architectural elements, the effects it can have on the materialization of activities were not as carefully considered. The primary flow of traffic follows the northern perimeter of the site and, therefore, so does most of the features. The ledges and wall offer showcase space along this highly visible route, and the circular seating is useful because of its convenient location. However the location of these elements in such close succession forces the activities which rely on public exposure to compete for space in the small portion of the site where this movement takes place. Many activities such as busking, markets, and panhandling thrive on the traffic, yet others, like skateboarding and loitering, are inhibited by it. Thus these other activities, which are deterred by the public eye but still required the architectural elements, are either pushed to the ill-equipped, neglected corners of the space or banned entirely

A similar situation is experienced by the elements of the site that do not serve this main pathway. Much of the West Side, along with the catwalk, does not contribute directly to the main route and so not only is their use less, but their potential contribution and effect on the site is rarely considered as well. These 

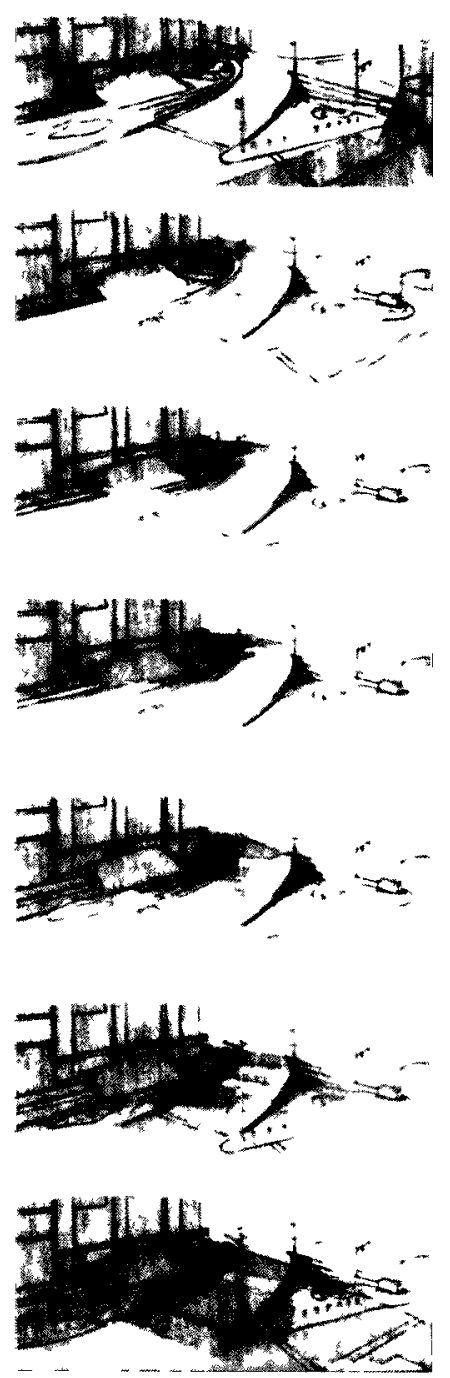

Figure 5.5

Sun study. Understanding the rules of the site elements are necessary for the Underpass to fulfill its purpose as a pedestrian link by providing wheelchair and bike accessibility, however surveys and observation journals reveal that even though these connections are vital, the routes are frequently misunderstood as there is no signage indicating the available routes and many paths dead end or loop around. ${ }^{62}$ These secondary paths currently do not sufficiently support the main ones and so the system remains underutilized and the site unable to flourish.

Had these elements been carefully contemplated and created as a result of playful rule manipulation, they could have provided necessary services while at the same time engaging the entire space and inspiring usage. Similarly, the renovation's response to the Underpass's geographical location is another example of this shortcoming. Due mainly to the surrounding built environment, the East Side of the site is the only portion that receives adequate sunlight; while the current design acknowledges this by placing the lingering elements (the circle seating, the ledge, etc.) in the areas which receive natural light, there was no attempt to provide sunlight where it was missing. As much of the site is subterranean, it requires additional lighting which, if provided at all, was done so with large artificial blubs that are only lit at night. Further ignorance of the rules stemming from the site's geographical location is seen in the treatment of the Covered Section. In addition to the inferior lighting strategy, the space beneath is grey, inconvenient and experiences draining issues. Moreover, the Covered Section of the Underpass has created a unique sound environment and awkward viewpoints that remained largely ignored in the current design.

A main reason panhandlers choose to perform in this area of the Underpass is because the amplification of sound is perfect for acoustic instruments. The structure reflects the sound of activities within it and effectively directs and channels it to almost the entire site. When it is combined with the sounds reflected off the wall of the former train station, this channeled sound further influences the emergence of activities in the space and creates a complex sound environment throughout the site. The potential for activities, especially those of a performance nature, are also impacted by the space's sight lines; a particular concern for a space that is divided by a large visual obstruction. However, even if the Underpass's design

\footnotetext{
${ }^{62}$ Refer to Surveys and site journals in Appendix B
} 
is altered to solve the issues pertaining to its physical condition, it will still suffer from the confrontation of the formal and the informal. The sheltered and highly public below-grade condition fosters informal activities, yet it is these activities that the formal community actively conspires against.

The elimination of the informal from the site has resulted in many new regulations whose implementation has altered the Underpass's original condition. Among the additions are 24hour surveillance, fences, lights and signs prohibiting skateboard and jaywalking. The only indication that now remains of the informal uses of the site are glimpses of street people panhandling before security appears, fresh paint covering graffiti, and garbage that does not make it to the can. ${ }^{63}$ Yet these signs, as well as those prohibiting various uses, are indicative of the site's embedded potential. The reality of removing the informal from the site has caused it to see little use, particularly in the winter when the activities of the DRBIA do not take place. To have the Underpass reach its full potential, both communities need to be accommodated and given the opportunity use the space.

\footnotetext{
${ }^{63}$ Refer to Surveys and site journals in Appendix B
} 
These activities are themselves architectural in the sense that performance gives form to space This space is constituted in performance Space thus adapted is different from staging the city as theater, treating an urban setting as a stage set The performance itself is architectural

-Barbara Kırshenblatt-Gımblett, Performıng the city Reflections on the Urban Vernacular 
THE URBAN PLAYGROUND

THE PROJECT PROPOSAL

Understanding the Underpass by way of its inherent rules not only helps to comprehend this leftover space, but also offers the basis upon which the indeterminate quality of the architecture built within is established. The multiple determinate programs which currently occupy the space outline these many spatial possibilities - suggesting which areas of the site are most used for what events and giving clues as to what changes and additions are required. The users and therr programs that inhabit the Underpass not only influence the design of the architecture, but also provide the foundation upon which it develops. Yet, designing an architecture for indeterminacy does not end at erecting a structure that can fulfill all of its prescribed functional needs. Instead it means creating an architecture that additionally promotes many of the contingent potentials embedded within a space through the act of play. This thesis explores how to encourage the users' imaginative play with and within an architectural space. It is the playful encounters of the varied users' programs and architectural tectonic elements, within the space and with each other which provide the project with the capability to be indeterminate. Through this layer of un-prescribed space usage, this thesis project finds its indeterminacy.

\section{THE PLAYERS I CONTRIBUTORS TO THE DESIGN}

For the Underpass, the list of probable, determinate activities comes from both the DRBIA and on-site observations. The promary activities focused on for the development of the project are extracted from the DRBIA's desired programs list ${ }^{64}$ and on-site observation journals: busking, homeless living, marketplace, performances (musical and theatrical) and gallery space (for both pın up art and graffiti). Other activities that are of a lingering nature, reading, writing, eating, etc., are also considered in the proposed design, as

\footnotetext{
${ }^{64}$ The Downtown Rideau Busıness Improvement Area "Call to Local Artısts " p 2
} 
Figure 6.0

Comparison of Current and Proposed Traffic

Patterns
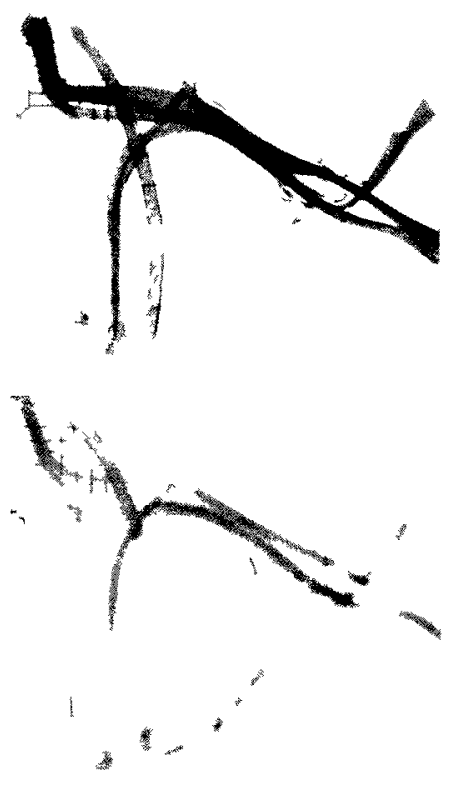

Figure 6.1

Diagram of Location of Potential Activities in Proposed Project

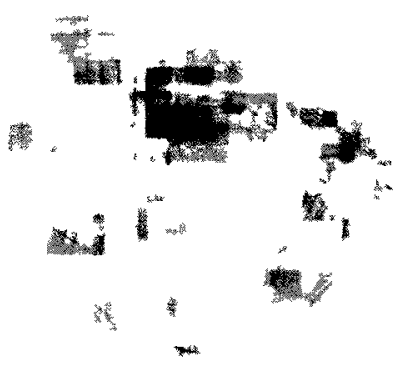

are the observed problematic conditions such as the lack of sunlight, drainage issues, traffic confusion and program confliction, which hinder the site. While many of these issues can be amended through the specifics of the design, the issue of program confliction and spatial obstruction required an architectural solution on a larger scale, and was thus the first to be addressed. It is the resolution of this condition which provides a base for the entire project.

If each observed program is considered a player, the reality of the site is that many of the site's activities, such as graffiti, busking, performances, walking etc. (see figure 5.3), flourish only under the Covered section. The result of this congestion is hostility between the users who are competing for this small portion of space while the majority of the site experiences little to no use. The reason for this is because each activity's personalized rules are complimented by the rules belonging to that particular section of the site. However, by introducing elements to the site that relieve the constraints of pre-existing conditions, it becomes better able to serve more activities and reach its full potential. Furthermore, the desired qualities currently located in only select areas can be extended, through architecture, to the rest of the space providing the hidden capacities of the underutilized areas the encouragement they need to thrive. This also allows the programs to spread out and occur simultaneously, instead of contending for the few specific portions that are most appealing and creating tension.

To begin the redistribution of activities and capitalization of the potential of the underutilized portions of the site, a viable way to access them that does not require a detour or backtracking must be established. With the natural desire for a link already dwelling in pedestrians attempting to navigate the site, the existing traffic light allows this need to be solved architecturally through the implementation of a crosswalk at the bottom of the traffic ramp. Pedestrians will have the ability to circle the entire site without having to turnaround, and with no expense to drivers. Furthermore, the use of the features not located on the northern border, such as the catwalk, will increase as it is no longer an inconvenience. With the implementation of this one element, public exposure is brought to more areas of the site, providing more practical space for the many activities that thrive on this condition. 


\section{Figure 6.2}

Concept Model. Exploration in the transformations of one form
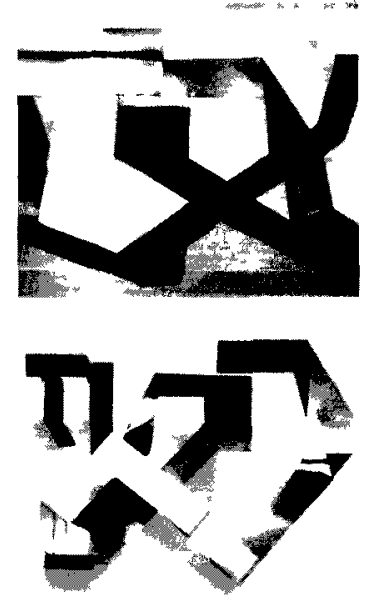

Figure 6.3

Diagram Proposed Gestures.

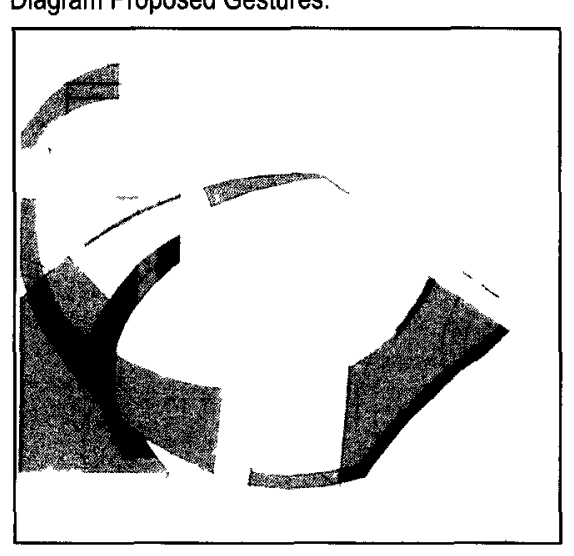

THE PLAYGROUND I ONE FORM, INFINITE POSSIBILITIES

The increase in accessibility and public exposure to the neglected areas of the Underpass combine to create more opportunities for play to take place as these previously void spaces are now more practical for use and thus more appealing to users. This thesis proceeds by further experimenting with how the new pathway can be more than a passage of travel. The pathway provides a gestural base, continuously encouraging different events to happen through the act of play. Susan Linn, when referring to the multiple potentials of one object in the eyes of a child, wrote that a child is able to see an object for what it is and what it could be. This, however, does not imply that every child sees the same potentials in an object; reality, in fact, depicts the opposite. While many children will play with an object in a similar way, there is no finite amount of possibilities for use. To them it is indeterminate. Architecturally, this thesis manifests this phenomenon through the continual transformation of one continuous gesture as it moves through the site. A single form repeatedly translated can create multiple potentials for use without dictating what those uses must be; similar to an object whose form can be used in several ways in the play of children. Furthermore, this adaptation not only provides the opportunity for play, but also inspires it. Initially, certain uses are obvious, however, the unrestricted transformations of the form suggest to users the potential for other activities and prompt the users' imaginations to further consider the possibilities the form has to offer.

The architecture designed for the Underpass is composed of two main gestures which move throughout the site, weaving around the existing features and each other. Each gesture continually transforms itself as it travels throughout the site, adapting its form to respond to the space and create potentials for use. The gestures' changes in height, size, orientation, and texture challenge the standard forms thought to be required for certain activities and excite the users' imaginations as to the possibilities embedded in each gesture. 


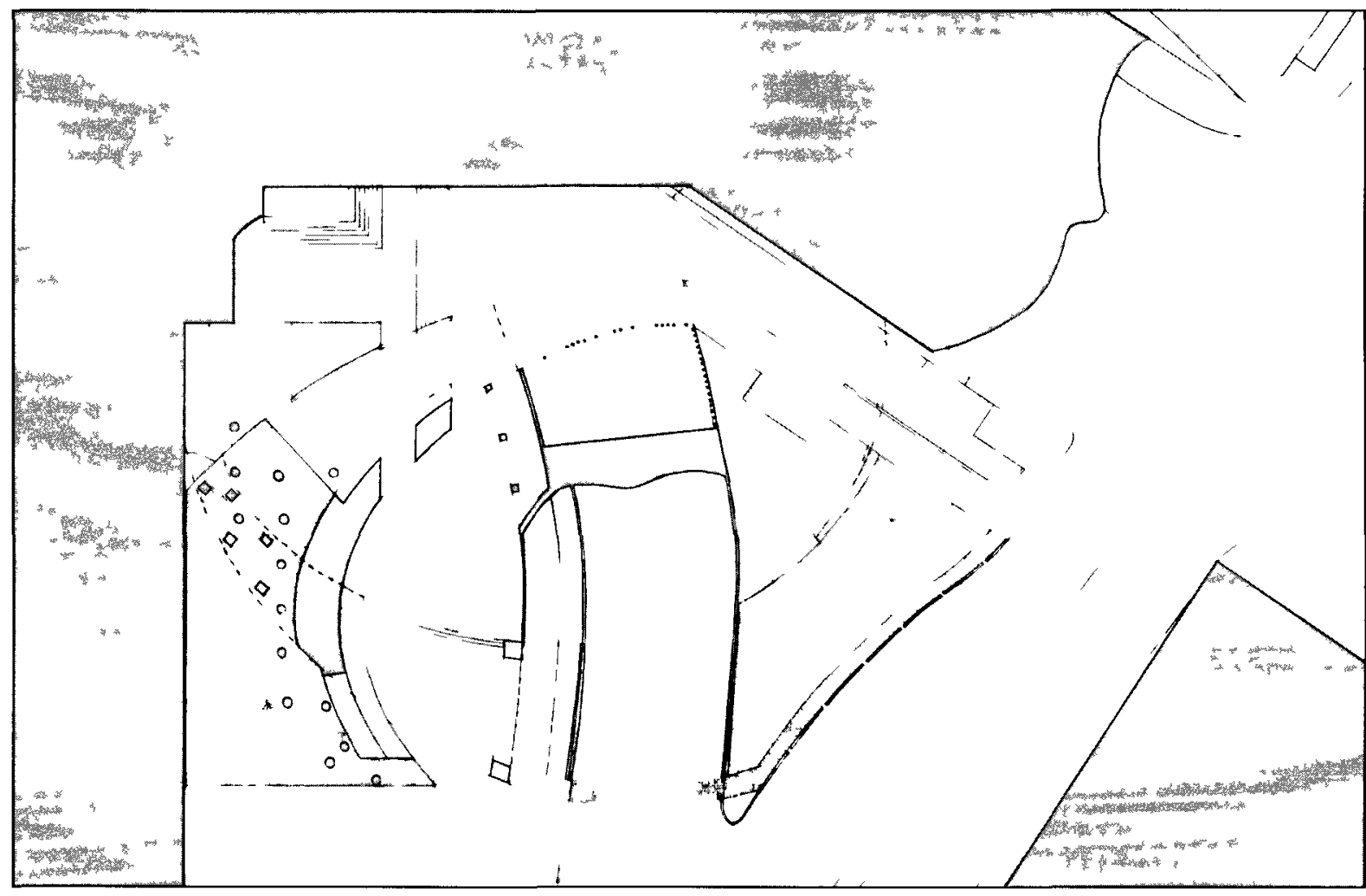

The first gesture is a Sweep. It starts at the highest elevation of the site and gradually descends eastward as it contınues through, eventually sınking below grade along the site's Colonel By Drive border. The second gesture is an Arch. It begins in a vertical orientation against the wall of the former train station twisting to temporarily become horizontal as it dips under the bridge and finishing as vertical, once again, In the Eastern section 


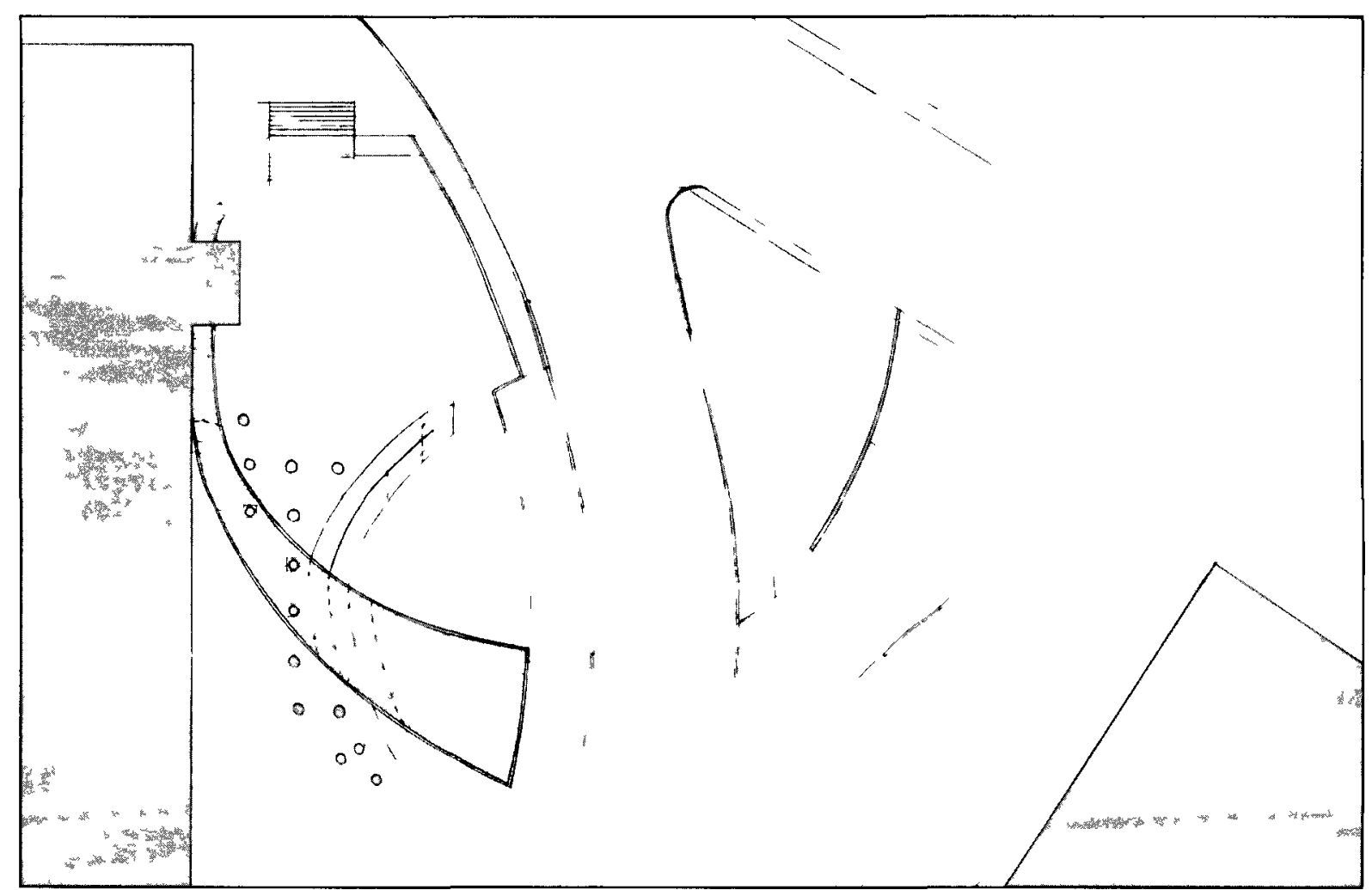

As each gesture moves through the site, it aims to resolve the problematic conditions previously mentioned as well as encourage the potentials inherent to the space. In the western section of the trees, the Sweep creates an elevated, highly visible area, either to view or be viewed, while also providing the pedestrians an opportunity to experience the site without feeling oppressed by the automobile traffic. This Sweeping gesture also completes the crosswalk implemented at the end of the ramp and converges with 


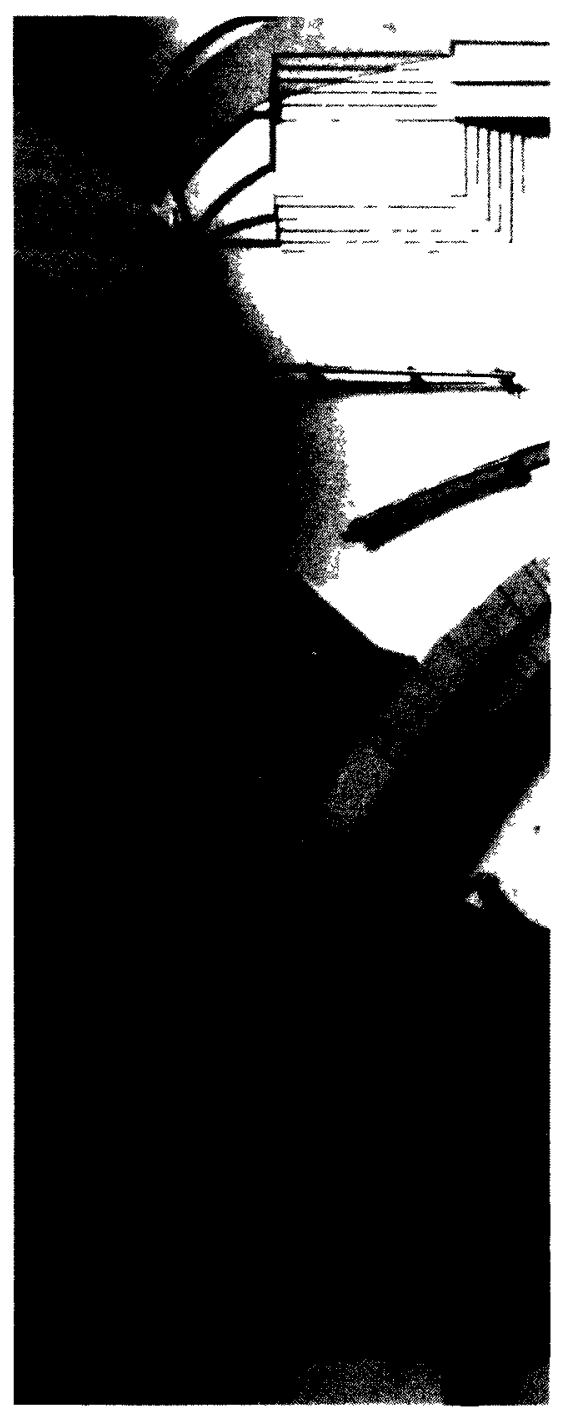

Figure 6.6

Final Model, The Western Section the Arching gesture to create a space of lingerıng in the sun of the Eastern section. The Arch begins by engaging the wall of the former train station before it slıps underneath the Sweepıng gesture, where the convergence produces pockets of space of varying intımacy. The Arch gesture continues under the bridge, where it creates a solution for the poor drainage situation and the lack of natural light. Finally the Arch resumes a vertical attitude in the Eastern section for both climbing plants to grow on, providing shade in the summer yet allowing sun to penetrate in the winter, and art to be displayed all year round.

\section{THE PLAY I THE ARCHITECTURE OF THE INDETERMINATE}

The final element completing the Underpass and its architecture's transition into its desired indeterminate state is materiality. The inspiration for play that arises from the project's transforming gestures is brought to its full potential through both the materials chosen to physically manifest the forms and the techniques used apply them. For this reason, it is crucial that the selected materials appropriately respond to the theories put forth by this thesis. The primary material chosen for this project is stone, both for its ability to satisfy the technical requirements of the architecture and because of its close association to the leftover cycle, namely the large quantities of material considered waste, in spite of its potential for use. The use of this leftover material visually reinforces the concept that there is value in what is deemed to be useless, and the various creative techniques used to shape and apply this material will also demonstrate the potential it embodies, excitıng the imagination of the users.

To be more specific the stone used is locally quarried sandstone because of its layered composition, varled aesthetics, proximity to the site, and abundant supply. It will be accentuated by corten steel, concrete, and structural glass. As the Sweep and Arch gestures move throughout the site, the materials chosen will transform with it, through the use of techniques observed in precedent studies. Workıng together, the steel and the sandstone shift fluently between structure, surfacing and art (sometimes 


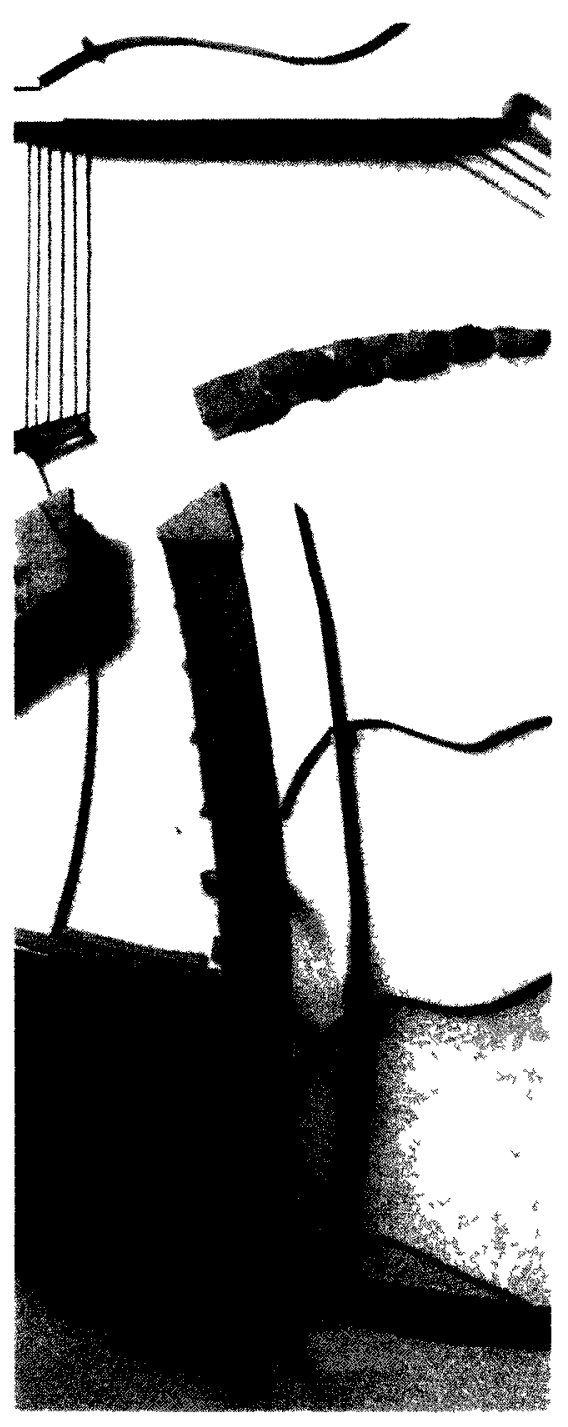

Figure 6.7

Final Model, The Middle Section serving as multiple simultaneously) to create the language of the forms as they move through the site, constructing playfully inspiring experıences.

These experiences arise at moments of contact between the implemented architecture and the existing. The first sub-category of these moments focuses on the encounters the architecture has with the nature of the site. The Arch gesture begıns with a steel trellis and stone set in grass collaborating to suggest a twisting of the landscape. The grass gives way to plants which climb the wall of the former train station and propose a shift of the landscape from the horizontal to the vertical. Further along the Arch gesture, the user experiences a forest of wood and stone trees, the latter providing support for the above Sweeping gesture. Here, while the stone performs its necessary structural function, it mimics the existing trees, much like the stone columns in Gaudi's Park Güell, and creates an ımagınative environment for visitors.

The second genre of moments pertains to the new architecture's collision with the grade of the site. In some instances the meetings are subtle and gradual as in the case of the Sweep gesture smoothly carving a path in the Eastern section as it descends slowly below grade. The stone paving the path is simply set into the earth through which the gesture cut. Similarly, the stone which delineates the shape of the Arch gesture on the landscape of the Western section, is also laid in the earth upon which the gestures rests, and the stone indicating the beginning of the Sweep is set into the concrete of the stairs. In other occasions the confrontation is not subtle but powerful and sudden. The Arch gesture abruptly plunges towards the existing concrete and upon contact, the stone seemingly shatters. Instead of being discarded, the resulting fragments of the colourful sandstone are then taken and arranged in the concrete, creating beautiful works of art, while at the same time carrying the shape of the gesture forward and underneath the bridge. Here, at the lowest point of the site, the stone again punctures holes in the surface of the concrete for the purpose of creating pockets within which water can accumulate while waiting to drain. The pools also provide a naturally reflective surface for afternoon light to bounce off illuminating the dark space. 


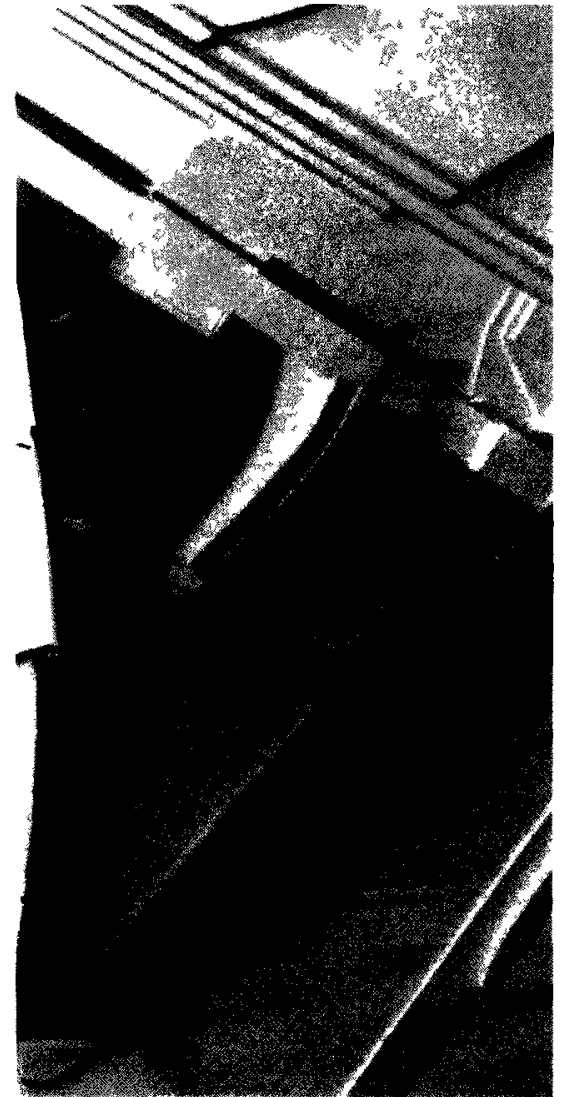

Figure 6.8

Final Model, The Eastern Section.
In addition to resolving problematic conditions, the pools of water also signify one of many ways the gestures interact with the road's influence on the site. Where they meet the road directly, the gestures first encounter the barriers - solid masses of concrete which cast an oppressive shadow over the site. At this moment, the gesture smashes through the barrier and broken, leftover pieces of sandstone are bundled together in a gabion to fill the hole. The value of these irregular pieces lies in their inability to lie flush with each other thus allowing the sun to penetrate the barrier and supply the site with more light.

Yet while the collection of these moments displays the part materials can have in architecture, particularly in an architecture of potentials, there is another role that it fulfills as well. The materiality of the site is the strongest communicator of which areas are meant for use. In the pre-existing design, the material language of the Underpass clearly tells which areas were deemed useful and which were considered to be waste. It is therefore imperative that the materiality of the new architecture express intent toward those areas created as a result of the gestures' formation and movement through the site, though are not included in them. The dry stone access ramp of the Sweeping gesture's stone tiled belvedere, for example, not only provides wheelchair and bike access and structural support to the platform above, but also designates the pocket of space in-between the two gestures as a potential playground. The sloping wall transforms the would-be negative space into a public area suitable for performances, markets and gatherings. Through the materiality, the leftover spaces created by the gestures can reversibly become the desired product. Here, and throughout the entire site, the architecture and its materiality recognizes the leftover as potential and promotes it as such. It is this duality that leads architecture towards play and ultimately indeterminacy. 


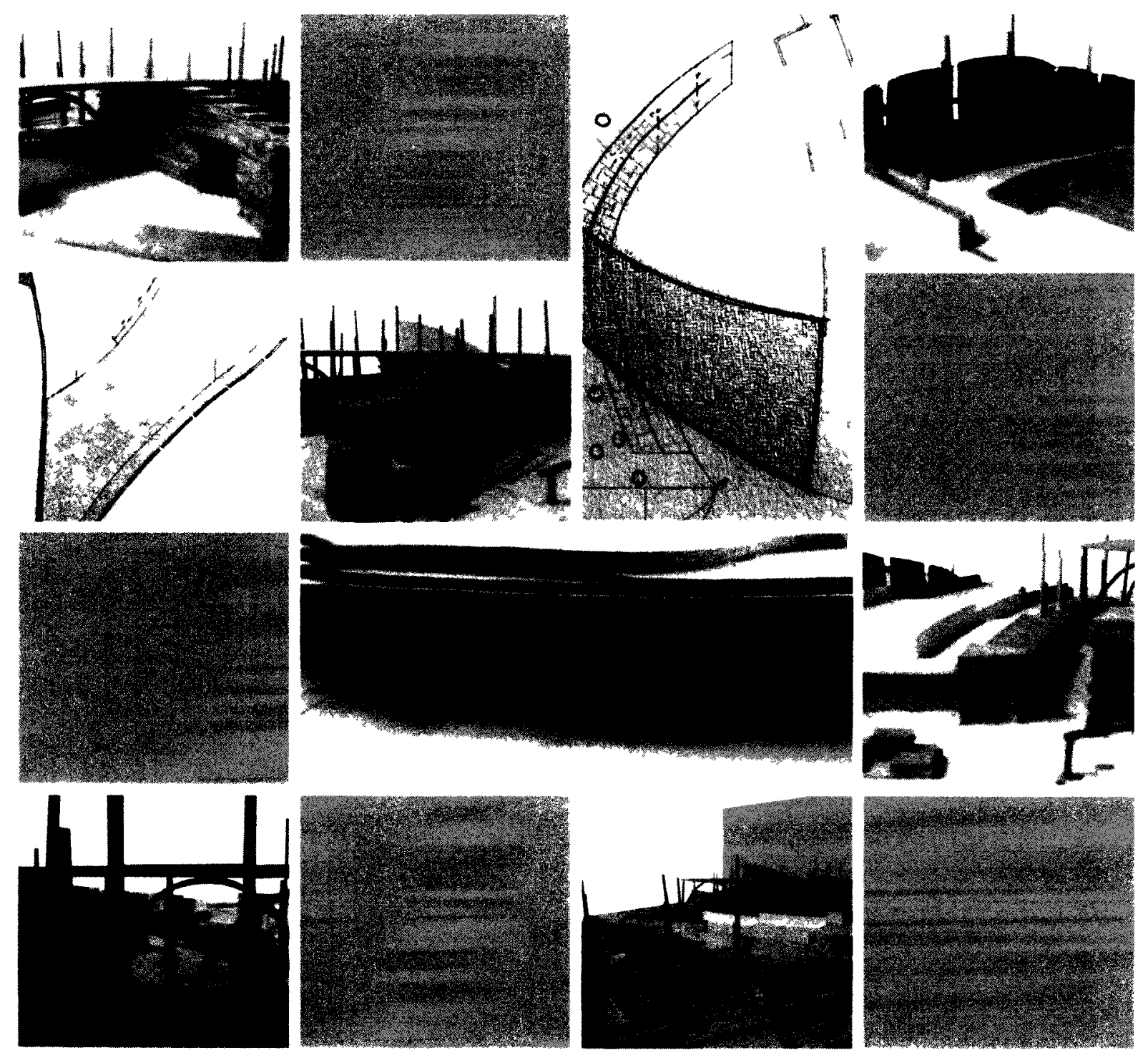


The Architecture of Transgression transgresses many of the boundaries that were imposed on the built environment, especially public space. Moreover, it opens different spaces in the boundaries of the architectural and planning professions, in the boundaries of the materials and techniques that are being used to shape spaces, in the boundaries of the fashionable form and aesthetics, in the boundaries of the social and political environment which this architecture produces and is produced by. And lastly the Architecture of Transgression transgresses the conception of what architecture is and what it is not. The Architecture of Transgression provides what architecture and planning failed to, where they created a void.

Gill M. Doron, The Dead Zone and the Architecture of Transgression 


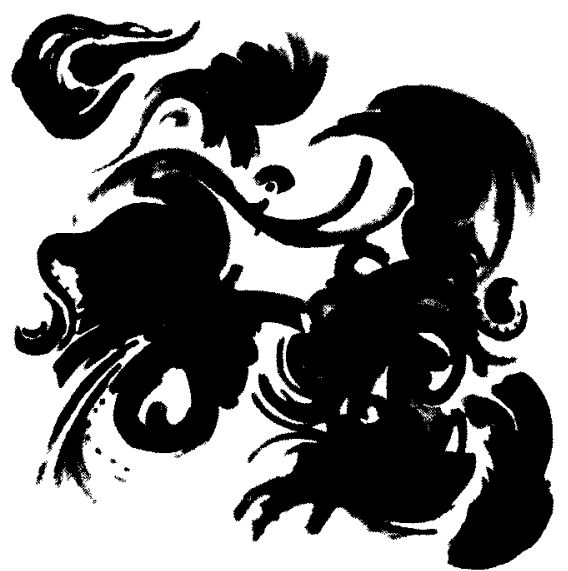

The inability of Junkspace to produce architecture that stimulates participation and expression lies in our inability to imagine it. By uncovering the buried layers of play, the architect is able to finally see their reflection in the spaces that once terrified them. Here, the process of the architect removing his subjectivity towards the project is not scary for him because he too is aware of the potential these spaces have to offer outside the determinate. The rediscovery of play and its infusion into architecture produces a complimentary architectural implementation for indeterminate leftover spaces. While the architecture is designed to embody the rules of play, its ultimate end is to reveal the inherent indeterminacy in leftover spaces by allowing play to take hold. By designing with the determinate in mind, though not naming it as such or limiting it too, playgrounds have a foundation upon which they can manifest while the users remain free to experience the space. Imaginative forms and creative material application refrain from dictating the use of the space and allow programs to [re]define their own spatial forms. Architecture founded on play is not only able to embrace it, but indulges it, inspires it and becomes it in the hopes that others will other will play along. 
APPENDIX A I glosSARY.

APPENDIX B I SITE JOURNALS.

APPENDIX C I LefTOVER MAPPING.

APPENDIX D I SURVEYS. 


\section{INDETERMINACY IIn-Di-tur-muh-nuh-seg]}

These are elther spaces in-between or at the edge

They have no officlal programme or usage and as such they trigger and embody limitless choice and desires.

They seem tc live in a temporal break a hiatus and exist in the con tinuous present - however they are ronthuousiy changing

Their aesthetic is of disorder

As marginal spaces in both spatial and socio economic terms these spaces embody 'constitutive outside' in their relationship to the rity and betieen the brious inhabitants

These spaces as other to the city

They are assumed to be an unproductive space but t can still be profit able as a speculative space, and productive in a way that cannot be quantified financially. perception is made of breaks absences dislocations as eil as by the produce papacity to produce patchworks of varrous contingent sorids. it is the in-between state that make the impos. sible, supernatural and marvelous visible

$$
\text { Dapootin? }
$$

Figure A.0

Indeterminacy Defintion from sources not definitelv set down not fixed left doubtful;

not determined by mollves acting freely.

$$
\text { acting freely. }
$$

It is about experiencing the City through what has been cast off and highlighting these sites as paradoxical spaces of freedom caught belween the dual processes of urban progress and perpetual degradation

Such sites and spaces are not waste. Thi y can be described as Junkspace but rather than being associated with the throwaway consumer culture of junk Mall food architecture as espoused by Koolhas junk here returns to its roots as differ. entiated from rubbish or waste due to its potential for reuse. It is a junk space of potential, awaiting re-entry to a system of value

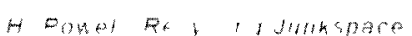

Leftover spaces have an inherent potential of indeterminacy. An existence in the gaps of cityscapes and of time allows these spaces to operate in a continuous present and a constitutive 'outside' condition. This condition equips these spaces with the ability to be used for an infinite number of activities at any moment. These

spaces are filled with potential and waiting to be discovered.

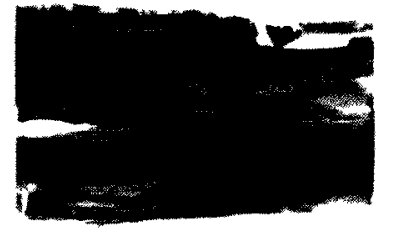




\section{LEFTOVER I [Left-oh-ver]}

the vacancies and absences in perception are assimi. lated and de-singularized into homogenized and potentially controllable texture of events. The goal of reason is if redistribute methodicallv the occasional elimination of picnolepsy to deny to particular absences any active value.
Junkspaces entroptc plan, as fillck io consume each of these sites of playful re-con struction. remaining over, not used up or disposed of something remaining over portion of some article of food left over from a meal a survivor

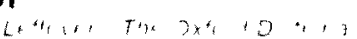

peculfar spaces in the bult envilonment which have been labelled waste-lands, derelict areas, No man's land, Dead Zones, urban voids, Terrain vague etc. These terma refer to places inich are neither slums (with poor but defined communities) nor open spaces in the city nor natural ones. These spaces are for example disused harbours and liain yatds abandoned barracks closed mining sites or industrial areas abandoned neigh bourhoods emply lots spaces at the edge of highways and under bridges etc

They levealed that the wasteland was actually not a waste at all; they were also an asset; they were in (informal) use; they were havens for wildlife. Nevertheless although the majorlty of the wastelands proved to be in use the conclusion of the research was that something needed to be done about this waste of land.

Figure A.1

Leftover Definition from sources abolishing these places by re planning redeveloping revital ing and renarsanciation will not delete the systems that produced these 'voids' and waste. These strategies and their methods are part of the same economic, social, political and planning systems that created these places from the beginning. Replanning redeveloping revitalizing and Renaissanciation Will simply erase the evidence of the crime futhermole it will exterminate the victims who found refuge in the waste

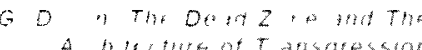

A leftover is a pocket of unused space, lacking identity and created in the wake of a programmed space. They are often considered to be wastelands, deadzones, junkspace, etc. because their true value a speculative space is ignored as it is not financially profitable. Leftovers are constantly generated because their indeterminate quality goes

undiscovered and the process that created them in the first place

is being used to 'erase' or 'fix' them.

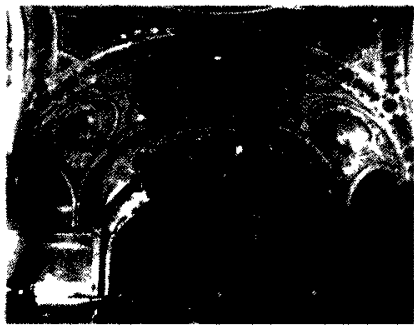




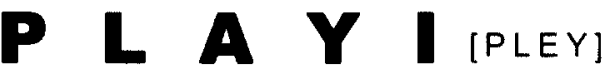

principle that leads children to invest a great deal of passion in an imper. sonal situation governed by rules and to think of expression in the situation as a matter of the remaking and the perfecting of those rules to give greater pleasure and promote greater sociability thth othels

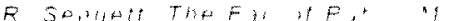

Brisk free movement exercise by way of amusement mimetic action dramatic performance spectacle on stage of a story performance of a mustcat instrument

Play is a voluntaryactivity or ocrupation expcuted vith certain fixed limits of time and place according to rules freely accepted but absolutely hinding having its aim in itself accompanled by a feeling of tension loy and the conscious ness that it is different from ordinary life

play thrives in the intersection between the inner world of tantasy and inner experience and the external world that exists in time and space it exists nether wholly in the inner no wholly in the nuter - but it can shape both

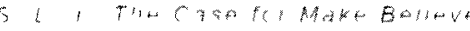

you are not locked into a specific

Figure A.2

Play Definition from sources

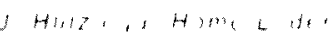

Play is done for its own sake.

it is not obligatory.

t makes you feel good.

you loose all sense of time and exist completely in the moment

rou cease beina self conscious as vou can become a different self way of doing things and often stumble upon new vays

Play does not need rules

Play is a voluntary activity that is accompanied by good feelings, distinct from everyday life and done for its own sake. It is carried out in a time and space of its own, separate from other activities and protected by

the rules. These rules define and advance the game yet are also malleable.

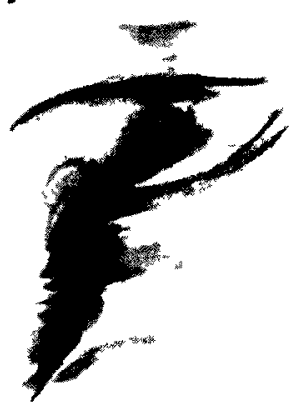




\section{PLA Y G R O U D I [pley-ground]}

It is finally secluded play has special spaces and time periods shich set is apat from othel actilties

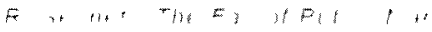

the early stages of play are follnded on the abllity to create worlds that no one else can see these worlds are created by a child s capacity to simultane. ously recognize an object for what it is and what it could be.

$$
=L \text { it Cusp fir Mine Be iave }
$$

could be seen as the antithesis of Junkspace as the fallout from this system of Perpet ual degeneration-what Junkspace the pro gramme regurgitates and spits out or hat couldn tconsume as vet

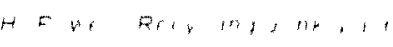

all are in form and function PLAYGROUNDS

le forbidden spots solated hedged round hallored within which special rules obtain. All are temporary worlds within the ordinary world, dedicated to the per. formance of an act apart.

Inside the playground an absolute and peculiar order reigns.... it creates order. is order. Into an imperfect world, and into the confusion of life it brings a temporary, a limited perfection.
They seem to live in a temporal break a hratus and exist in the continuous present ho ever they are continuously changina

As margmal spaces in both spatial and socio economic terms these spaces embody 'consti. tutive outside' in their relationship to the city and between the various nhabitants

These spares as other to the city

Transformed into places of living, creation and performing by means and technologies that are available to anyone.

G Dr an Tinsqresciva fiold Jounat

A playground is a world apart from the ordinary while existing within it. It is what leftover spaces become when they break free of the perpetual leftover cycle and discover their indeterminate potential. It is a place where the rules are made to suit the wants and needs of the player.

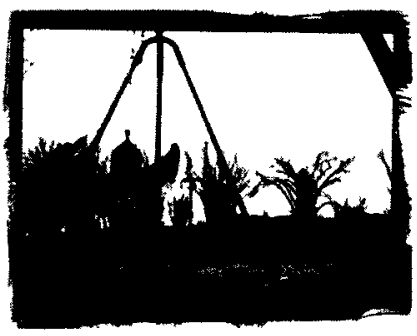

Figure A.3

Playground Definition from sources 


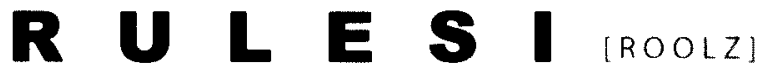

These rules in their turn are a very impor. tant factor in the play concept All play has rules. They determine what "holds" in the temporary world circumscribed by play.

The rules of a game are absolutely binding and allow no doubt as soon as the rules are trans gressed the thole play world collapses the game is ovel The spoll-sport shatters the play "orld itself By withdrawing from the game he reveals the relativity and fragility of the play-world in which he had temporaril tence of the rule community

The specific acts in play, however, are all aimed at the delay of winning, delay of termination The tools which permit children to delay, to remain in a state of play, are the rules... It is only by erecting rules that the children keep themselves free of the outside, non-play world. The more complicated the rules are, the longer the children are free."

In game play, malleability of the rules creates a social bond. To play lequires a freedom from the self but this freedom can be created only by rules which will establish the fiction of initial equality in power between the plavers

Figure A.4

Rules Definition from sources principle or regulation governing an act to control guide diect to confine within; to arrange or set in order

$$
\text { Rules The OxtitD is nuly }
$$

Begun by all from bith it's the very austerity of its tools, its rules, and its representations that paradoxically unleashes in the child pleasure and even passion

$$
\text { P Vumin Tho Aasthetics of Disampearan. }
$$

All play has rules; they are what defines it and keeps it free from the outside, non-play world. Rules must be accepted to begin playing, but they allow for infinite variation within. They are tools which permit children to delay, to remain in a state of play and their malleability creates a social bond. To break the rules is to shatter the playworld and reveal its fragility, because the essence of play is that the of play is that the
rules are kept. The rules are kept. The
rules protect the play-world.

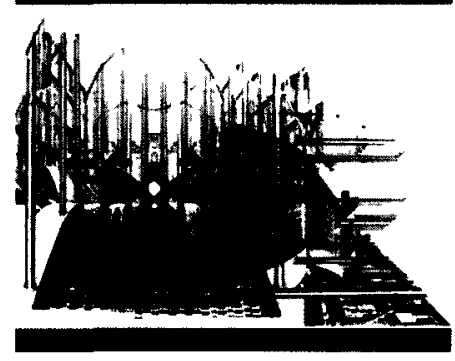


APPENDIX B ।

SITE JOURNALS.

10.18.10

Monday 3pm

Sunny with cloudy periods, Windy NW31

$10^{\circ} \mathrm{C}$

Duration: $15 \mathrm{mins}$

\section{Observations}

- Sitting on west side

- Only person l've seen ever sit for an extended period of time on this side

- Many newspapers on other side - people stop to eat lunch on east side

- evidence of graffiti painted over underneath bridge (pictures)

music playing (jazz); speakers located behind the cage

woman stops to read signage about the artwork

little to moderate foot traffic

- disheveled man on bike stops under bridge to smoke

○ stayed less than 10 mins $\left(3^{05}-3^{12}\right)$

- left in hurry

- others stopped to chat, didn't seem to be rushed

- garbage around site included: newspapers, receipts, guitar pick, cigarette buds etc.

\section{Speculations}

- site could be used for musical performance, food vending, newspaper vending, live art demonstrations, information displays

- suspect homeless know how long they can stay before getting in trouble

- disheveled people still prefer stopping under bridge

- temperature much lower under bridge (Bring a thermometer next visit)

- what would happen if the passage was physically divided in 2 ? 
10.22.10

Friday $2 \mathrm{pm}$

Cold, overcast, Windy

$4^{\circ} \mathrm{C}$

Duration: 20mins

\section{Observations}

- Sitting on west side

- offers the best views to site

- get weird looks for sitting on this side

- gives the impression that people don't linger

- is really cold; attracting attention to myself

- barely any foot traffic

- does seem to come in bursts; related to buses?

- Wind not as much of factor underneath bridge, but still felt on stairs

- traffic not very audible from site

- clean; barely any garbage

- busker showed up to play guitar, played 3 songs then another man came to speak to him (also homeless looking) and the two left relatively quickly in separate directions

- stayed less than $10 \mathrm{mins}\left(2^{10}-2^{16}\right)$; same amount of time as previous man from monday

- he came back, reading a paper $10-15$ mins later but did not play

\section{Speculations}

- the man wasn't allowed to play; he left too soon and the jazz recording was still on, he just played over it

- who will get them in trouble/reinforce the rules, and where that person is?

- what if introduce element of light during the day? Also would it heat up space at all?

- Suspect that there's a network of the space through people; another man alerted the guitar player... they have a support system, does it connect the spaces? 
- Is it worth trying to survey other indeterminate sites with underpass survey?

- Watch other sites to see what they're used for - look at appropriateness for my site

\subsubsection{0}

Wednesday $12^{30} \mathrm{pm}$

Warm, overcast, damp, no wind

$16^{\circ} \mathrm{C}$

Duration: $35 \mathrm{mins}$

\section{Observations}

- Sitting underneath bridge where ledges meet wall (common homeless person seat)

- Within 5 mins of sitting, was approached by homeless man (commenting on the music

- jazz playing through speakers again

- moderate to heavy foot traffic; picked up at $12^{40} \mathrm{pm}$; suspect due to lunchtimers going back to work

- most traffic heading east to west

- underneath bridge is colder, and wet, while other places are drying out, suggest drainage issues

- surveillance sign has city of Ottawa logo

- people do stop to eat lunch and read in eastern garden area; 3 people in $35 \mathrm{mins}$

- a man was begging at top of stairs on west side

- child climbs on ledges that I was sitting on

- many people look at cage; element of curiosity

- men from lafleur company were working on site; www.lafleur.ca

\section{Speculations}

- woman sitting in eastern garden trying to write/draw and was all hunched over; perhaps seating with broad arms to allow for writing

steps extending from east ramp to the bridge wall are narrow; perhaps to not allow for sleeping 
- what if extend ledges or 'steps' all around, through to stairs on other side?

- Perhaps not done to discourage sheltered sleeping

surveillance sign has city of Ottawa logo, suggests ownership 613-580-2580

- get a lot of weird looks from walkers, do only homeless linger alone?

11.2.10

Tuesday 2pm

Sunny, brisk, no wind

$7^{\circ} \mathrm{C}$

Duration: $10 \mathrm{mins}$

\section{Observations}

- Posted surveys: 2 onsite, 1 off.

- One were buskers generally set up, the other in the eastern garden where people are likely to pause

- Usual guitar playing busker was there, spoke to him

- Been playing for 7 years, without a permit, has much insight into the site

- Best times to busk is around Christmas and after work on weekdays; though traffic is heavy during lunch, people are pinched for time so won't stop

- Minimal graffiti was present on benches in eastern garden

- There as a man selling art at the top of the ramp on the eastern side, using the ledges to display work

\section{$\underline{\text { Speculations }}$}

- At what point does security just let them stay? (The frequent guitar player, the old man comfortably set up) 
11.30.10

Tuesday $10^{30} \mathrm{pm}$

Rainy, cold, wind from the east, $22 \mathrm{~km} / \mathrm{h}$

$1^{\circ} \mathrm{C}$

Duration: Walkthrough

\section{Observations}

- Display carts in middle are gone

- New guitar player busking

- Site is dirty, icy, grass weather fenced in

- Girl sitting on eastern ledges on phone

- The ledges stay dry in the rain

\section{$\underline{\text { Speculations }}$}

Certain areas of site always populated while other are always empty; perhaps site needs more covered space 
Using the Underpass as the center of the search, Ottawa's leftover spaces were sought out and recorded The condition of the spaces reflect the attitudes felt towards them and showcase the various stages of the leftover cycle.

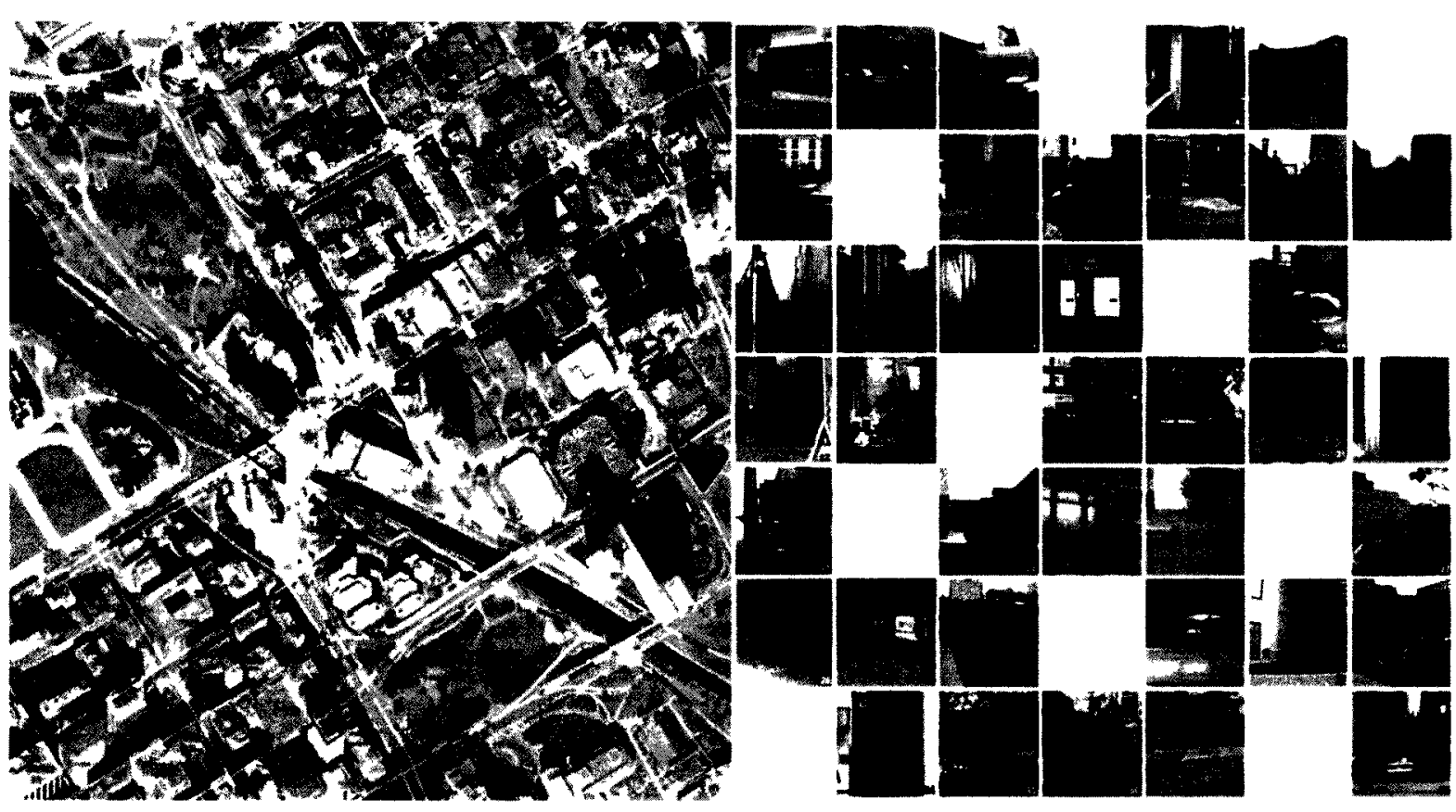




\section{Survey 1}

SURVEYS.

Do you come to the Underpass often?

Yes, on Business

Where did you just come from where are you going when next?

Vancouver

Normally how long do you stay? (Please give an approximation of time and reason of stay)

2-4 days

How and why do you use this space? If you could use it for an activity what would it be?

To get from one side to the other. Listening tomusic.

What do you like about this space?

The music provided by Marc

What do you dislike about this space?

Cigarette butts

If you could change it (add something, take something away etc.) what would you change and how? What would you like to see this space used for?

Clean up the cigarette butts

What do you think your friends and family would use it for? Why?

What do you think makes a space great? (What qualities do you like in a space?)

Human interaction

How do you think this space contributes to its urban surrounding?

Yes, with music by Marc.

Nov 2,2010

Female, Age 26-35

Does not Live in Ottawa

How does the weather/season affect how you use this space? Why?

$\mathrm{n} / \mathrm{a}$ 
Survey 2

Nov. 2, 2010

Male, Age 26-35

Lives in Ottawa

\section{Survey 2}

Do you come to the Underpass often?

Once/twice a week

Where did you just come from where are you going when next?

Back to Dalhousie

Normally how long do you stay? (Please give an approximation of time and reason of stay)

I pass through

How and why do you use this space? If you could use it for an activity what would it be?

Pathway and node

What do you like about this space?

Grade change

What do you dislike about this space?

No one here

If you could change it (add something, take something away etc.) what would you change and how? What would you like to see this space used for?

Make it more "subversive" - There is not much of that in "Official Ottawa"

What do you think your friends and family would use it for? Why?

Pathway

What do you think makes a space great? (What qualities do you like in a space?)

Underground area - only in the area

How do you think this space contributes to its urban surrounding? Pathway

How does the weather/season affect how you use this space? Why?

Not sure 


\section{Survey 3}

Do you come to the Underpass often?

No - usually because it has hobo's in it that either ask for money or look at you creepy like, I prefer the other side of the street if $\mid$ can do it

Where did you just come from where are you going when next?

Usually I am coming from the mall and walking to sparks street (so I dont want to cross the road, but forget that you have to take the underpass...

Normally how long do you stay? (Please give an approximation of time and reason of stay) As long as it takes to get out

How and why do you use this space? If you could use it for an activity what would it be?

If it wasn't so sketchy I think it would be a great place for art exhibits, or the like. Music could also be played to make it more lively-also would be a great place for a game of dodge ball - or squash

What do you like about this space?

I like that it is outdoor but under cover - allows for multiple uses

What do you dislike about this space?

That sketchy hobo's use it and it usually smells a bit

If you could change it (add something, take something away etc.) what would you change and how? What would you like to see this space used for?

Public activities - anything that gets the public involved and using the space more. I wouldn't change the space, I think

that something needs to take it over... and adapt within it

What do you think your friends and family would use it for? Why?

I think family could use it as a place to let the kids run around without the fear of them running into traffic - a space that could contain kid activities

What do you think makes a space great? (What qualities do you like in a space?)

A space should be vibrant, and keep your attention - make you look at it, not blend into the background

How do you think this space contributes to its urban surrounding?

I think it allows for more pedestrian access, and encourages people to walk (because they are separated from the road 


\section{Survey 3}

Nov. 30, 2010

Female, Age 19-25

Lives in Ottawa
How does the weather/season affect how you use this space? Why?

You would take the space more when it is very windy or rainy... because it gives you a chance to get out of it when you have to walk somewhere

\section{Survey 4}

Do you come to the Underpass often?

Pass under it about 15 times a year

Where did you just come from where are you going when next?

? (I don't really get this question; I just came from starbucks and I'm going to staples) but this question totally made me think of one the Nuit Blanche events (they had a giant chalk board and recorded ppls answers to questions like this I

can look up the name if its at all relate to your work)

Normally how long do you stay? (Please give an approximation of time and reason of stay)

Don't stay; purely on the way to/from somewhere else.

How and why do you use this space? If you could use it for an activity what would it be?

When walking from the Market/Rideau to Elgin or Wellington

What do you like about this space?

It's sheltered from the elements

What do you dislike about this space?

Feels cramped and cold/sterile

If you could change it (add something, take something away etc.) what would you change and how? What would you like to see this space used for?

bring light in, have it bike accessible

What do you think your friends and family would use it for? Why?

They wouldn't, they drive everywhere. If used, it would only be passing through.

What do you think makes a space great? (What qualities do you like in a space?)

Comfort, light,

How do you think this space contributes to its urban surrounding? 


\section{Survey 4}

Dec. 3,2010

Female, Age 19-25

Does not Live in Ottawa
At the moment, it doesn't seem to. Feels like a 'left over' space.

How does the weather/season affect how you use this space? Why?

There is much more hibernating in the winter, so I would avoid this space/wind tunnel? due to the cold. There is a lot of potential for the space in the spring/summer.

\section{Survey 5}

Do you come to the Underpass often?

Not often, maybe 2-3 times a year

Where did you just come from where are you going when next?

I came from Rideau Centre and I was heading towards the bus stop near Parliament Hill

Normally how long do you stay? (Please give an approximation of time and reason of stay)

Duration of the stay is about the time it takes me pass through. Approximately 3 minutes.

How and why do you use this space? If you could use it for an activity what would it be?

Use of Space $=$ Add culture by displaying installations

What do you like about this space?

LIKE = The location of this site is in a central part of the centre. There is a lot of potential for this area

What do you dislike about this space?

DISLIKE = The feeling of disorientation once I leave the space. (Let me know if this needs further explanation.)

If you could change it (add something, take something away etc.) what would you change and how? What would you like to see this space used for?

I would like this space to be integrated better with its surrounding. Possibly show more character with installations and such?

What do you think your friends and family would use it for? Why?

I think most people use it to go from the market to Elgin Street

What do you think makes a space great? (What qualities do you like in a space?) 
Survey 5

Dec. 11,2010

Female, Age 19-25

Does not Live in Ottawa

\section{How do you think this space contributes to its urban surrounding?}

The space adds a safety feature: Because the intersection is odd, the underpass demonstrates the consideration for auto traffic as well as human traffic

\section{How does the weather/season affect how you use this space? Why?}

In warmer seasons, people are more willing to explore the city and this space. For colder seasons, people use it just as a way to get from $A$ to $B$. 
Figure 0.0

Figure 0.1

Figure 1.1

Figure 2.0

Figure 2.1

Figure 2.2

Figure 2.3

Figure 2.4

Figure 3.0

Figure 3.1

Figure 4.0

Figure 4.1

Figure 4.2

Figure 4.3
Frontis Piece I Painting I 2008 I Katie Pyle

Frontis Piece I Photograph I 2011 I Katie Pyle

A Picture is Worth a Thousand Words I Image I 2011 I Katie Pyle

Leftover Spaces in Downtown Ottawa I Image I 2011 I Katie Pyle

Squatter Residence Freidrichshain, Berlin I Photograph I 2009 I Jared Hagens

Comparison of the spatial arrangement in Brunnen Str $6 \& 7$ and the conventional occupancy arrangement of a courtyard building I Image I 1994-1996 I Dougal Sheridan I

"The Space of Subculture in the City: Getting Specific about Berlin's Indeterminate Territories" Field. Vol.1 (1) ISSN: 1755-066

Signage posted in leftover spaces, Ottawa I Image I 2011 I Katie Pyle

Tacheless, Berlin I Photographs I 2009 I Katie Pyle

F\# Scale I Sketch I 2011 I Katie Pyle

Scenes from Finding Neverland I DVD Movie I 2005 I Miramax Films Corp.

Select pages from Antoinette Portis's Not A Box I Image I 2007 I Antoinette Portis I Not A Box.

Activities web I Drawing I 2010 I Katie Pyle

Landhausplatz by Stiefel-Kramer Architecture, Innsbruck I Photographs I 2010 I Günter

Richard Wett I "Landhausplatz." www.stiefelkramer.com. 2010.

World Park Complex by Steven Holl Architects, Seoul I Sketch I 2007 I Steven Holl I

"The World Design Park Complex." www.stevenholl.com. 2007. 

Marc Llimargas. Gaudi the Man and His Work. p193,196-197

Figure 4.5 Ceramic Mosaic at Güell by Antonio Gaudi, Bareclona I Photograph I 1999 I Marc Llimargas. Gaudi the Man and His Work. p183

Figure 5.0 The Underpass: The Leftover's Leftovers I Photograph I 2011 I Katie Pyle

Figure 5.1 Labeled Site Model I Image I 2011 I Katie Pyle

Figure 5.2 Photos of Site Sections I Image I 2011 I Katie Pyle

Figure 5.3 Location of Existing Activities I Decals on Plexiglass I 2011 I Katie Pyle

Figure 5.4 Current Traffic Patterns I Vellum and Paper Collage I 2011 I Katie Pyle

Figure 5.5 Sun Studies I Marker Sketches I 2011 I Katie Pyle

Figure 6.0 Comparison of Current and Proposed Traffic Patterns I Vellum and Paper Collage I 2011 I Katie Pyle

Figure 6.1 Diagram of Location of Potential Activities in Proposed Project I Image I 2011 I Katie Pyle

Figure 6.2 Concept Model I Aluminum and Plexiglass I 2011 I Katie Pyle

Figure 6.3 Diagram Proposed Gestures I Image I 2011 I Katie Pyle

Figure 6.4 First Level Plan of Proposed Architecture I Drawing I 2011 I Katie Pyle

Figure 6.5 Second Level Plan of Proposed Architecture I Drawing I 2011 I Katie Pyle

Figure 6.6 Final Model; The Western Section I Bass Wood, Copper and Bainbridge I 2011 I Katie Pyle

Figure 6.7 Final Model; The Middle Section I Bass Wood, Copper and Bainbridge I 2011 I Katie Pyle 
Figure 6.8

Figure 6.9

Figure 7.0

Figure A.0

Figure A.1

Figure A.2

Figure A.3

Figure A.4

Figure C.O
Final Model; The Eastern Section I Bass Wood, Copper and Bainbridge I 2011 I Katie Pyle

Final Project Imagery I Image I 2011 I Katie Pyle

Untitled I Painting I 2010 I Katie Pyle and Suzanne May

Indeterminate Definition from April Colloquium Slides I Image I 2011 I Katie Pyle

Leftover Definition from sources I Image I 2011 I Katie Pyle

Play Definition from sources I Image I 2011 I Katie Pyle

Playground Definition from sources I Image I 2011 I Katie Pyle

Rules Definition from sources I Image I 2011 I Katie Pyle

Map of Ottawa's Leftovers I Image I 2010 I Katie Pyle 
WORKS CITED I

Cormeir, Nick. Personal Interview. 25 Oct. 2010.

Doron, Gil M. “...badlands, blank space, border vacuums, brown fields, conceptual Nevada, Dead Zones..." Field. Vol.1 (1) ISSN: 1755-068, Sept. 2007.

Doron, Gil M. “The Dead Zone and the Architecture of Transgression.” City. Vol.4 number 2, 2000: 247 263.

The Downtown Rideau Business Improvement Area. "Call to Local Artists." 2010 The Underpass pdf. April 9, 2010.

Economic Development Department. "ERASE." City of Hamilton Brownfields Program. Accessed: Dec. 2010. URL: http://www.aboutremediation.com/PDFS/ERASE.pdf

Finding Neverland. Dir. Marc Forster. Perf. Johnny Depp and Kate Winslet. Miramax Films Corp., 2005 Gagne, Norm. Sales Supervisor for Merkley Building Supply Ltd. Personal Interview. Sept. 212010. Gilloch Graeme. Myth and Metropolis: Walter Benjamin and the City. Oxford: Polity, 1997. Huizinga, Johan. Homo Ludens. Boston: Beacon Press, 1967.

Kirshenblatt-Gimblett, Barbara. "Performing the City: Reflections on the Urban Venacular." Everyday Urbanism. New York: The Monacelli Press, 2008.

Linn, Susan. The Case for Make Believe. New York: The New Press, 2007.

Bergós, Joan, Marc Llimargas, Jordi Ribera I Bergós, Maria Antonietta Crippa. Gaudi the Man and His Work. Spain: Bulfinch Press, 1999.

Núnez, Juan Morell. “Gaudi and the Catalan Craftsmen of His Time." Living Gaudi. New York: Rizzoli, 2002.

"Ottawa's Homeless Fight for Right to Sleep in Underpass." CBC News. 31 Jan. 2008. Accessed: Oct. 2010. URL: http://www.cbc.ca/news/canada/ottawa/story/2008/01/31/ot-homeless080131.htm|\#ixzz11Uu2lng1

Portis, Antoinette. Not A Box. China: Harper Collins Publishers, 2007. 
Powell, Hilary. "Recycling Junkspace: finding space for 'playtime' in the city." The Journal of Architecture. Volume 10, April 2005: 201-221.

Sennett, Richard. The Fall of Public Man. New York: Vintage Books, 1978.

Seymour, A. "Hankey acquitted in Ottawa underpass stabbing." The Ottawa Citizen. 7 Nov. 2008.

Accessed: Nov. 2010. URL: http://www.canada.com/ottawacitizen/news/story.html?id=9afe0fc9-a86f4b0b-8828-a84b5b3addd7

Sheridan, Dougal. "The Space of Subculture in the City: Getting Specific about Berlin's Indeterminate Territories" Field. Vol.1 (1) ISSN: 1755-066, Sept. 2007.

Solé, Eduard. "The Park Güell (1900 -1914)." Gaudi and Barcelona Club. Accessed: May 2011. URL: http://www.gaudiclub.com/ingles/i vida/park.asp

Steven Holl Architects. "The World Design Park Complex." www.stevenholl.com. 2007. Accessed Jan 2011. URL: http://www.stevenholl.com/project-detail.php?type=masterplans\&id=99\&page=1

Stiefel Kramer Architecture. 'Landhausplatz.' www.stiefelkramer.com. 2010. Accessed: Mar 2011. URL: http://www.stiefelkramer.com/

Sweeney, James Johnson and Josep Lluis Sert. Antoni Gaudi. London: The Architectural Press, 1960. Thompson Micheal. Rubbish Theory: the creation and destruction of value. Oxford: Oxford University Press, 1979.

Virilio, Paul. The Aesthetics of Disappearance. Los Angeles: Semiotext(e), 2009.

White. Mason. "Atelier Bow-Wow: Tokyo Anatomy". Archinect. Features Article 56468. 2007. Accessed May 2011. URL: http://archinect.com/features/article/56468/atelier-bow-wow-tokyo-anatomy

Williams, Emma. "Spaces of Indeterminacy." The Theory Forum: Architecture and Indeterminacy. Nov. 2007. Accessed: Feb. 2010. URL:

http://www.shef.ac.uk/architecture/main/gallery/gal/diploma/theoryforum07/essays/emma williams.pdf 
SUPPLEMENTARY SOURCES I NON-CITED, CONTRIBUTING WORKS.

Benjamin, Walter. The Arcades Project. Boston: Harvard University Press, 1999.

Brown, Stuart. Play. New York: Avery, 2009.

Koolhaas, Rem. "Junkspace." October. Vol. 100 Obsolescence, Spring 2002: 175-190.

Lee, Pamela M. Object to be destroyed: The work of Gordon Matta-Clark. Cambridge: MIT Press, 2001.

Rowe, Colin and Robert Slutzky. "Transparency: Literal and Phenomenal." Perspecta. Vol. 8, 1963: 45-

54.

Smith, Peter. Children and Play. Malaysia: Wiley-Blackwell, 2010. 